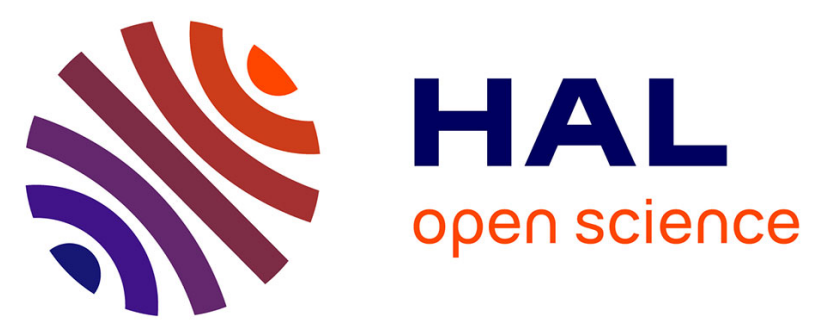

\title{
Accuracy and precision of cryogenic limb array etalon spectrometer (CLAES) temperature retrievals
}

\author{
John C. Gille, Paul Bailey, Steven T. Massie, Lawrence V. Lyjak, David P.
} Edwards, Aidan E. Roche, John B. Kumer, John L. Mergenthaler, Michael R. Gross, Alain Hauchecorne, et al.

\section{To cite this version:}

John C. Gille, Paul Bailey, Steven T. Massie, Lawrence V. Lyjak, David P. Edwards, et al.. Accuracy and precision of cryogenic limb array etalon spectrometer (CLAES) temperature retrievals. Journal of Geophysical Research: Atmospheres, 1996, 101 (D6), pp.9583-9601. 10.1029/96JD00052 . insu03112848

\section{HAL Id: insu-03112848 \\ https://hal-insu.archives-ouvertes.fr/insu-03112848}

Submitted on 6 Feb 2021

HAL is a multi-disciplinary open access archive for the deposit and dissemination of scientific research documents, whether they are published or not. The documents may come from teaching and research institutions in France or abroad, or from public or private research centers.
L'archive ouverte pluridisciplinaire HAL, est destinée au dépôt et à la diffusion de documents scientifiques de niveau recherche, publiés ou non, émanant des établissements d'enseignement et de recherche français ou étrangers, des laboratoires publics ou privés. 


\title{
Accuracy and precision of cryogenic limb array etalon spectrometer (CLAES) temperature retrievals
}

John C. Gille,1 Paul L. Bailey,1 Steven T. Massie,1 Lawrence V. Lyjak,1 David P. Edwards, 1 Aidan E. Roche, 2 John B. Kumer, 2 John L. Mergenthaler, 2 Michael R. Gross, 3 Alain Hauchecome, 4 Phillip Keckhut,4,5 Thomas J. McGee, 6 Ian S. McDermid, 7 Alvin J. Miller,5 and Upendra Singh ${ }^{3}$

\begin{abstract}
The Cryogenic Limb Array Etalon Spectrometer (CLAES) measured emission from the $792 \mathrm{~cm}^{-1} Q$ branch of $\mathrm{CO}_{2}$, from which temperature distributions in the stratosphere and low mesosphere were derived. Here we briefly review the measurement technique, concentrating on aspects that affect the temperature determination. Comparison of many pairs of retrievals at the same location (near $32^{\circ} \mathrm{N}$ or $32^{\circ} \mathrm{S}$ ) measured on sequential orbits (time separation of $96 \mathrm{~min}$ ) shows a precision ranging from approximately $0.8 \mathrm{~K}$ at $68 \mathrm{mbar}$ to about $3.5 \mathrm{~K}$ at $0.2 \mathrm{mbar}$, which agrees with simulations incorporating random noise and short-period spacecraft motions. Comparisons of globally analyzed CLAES data with National Meteorological Center (NMC) and U.K. Meteorological Office (UKMO) analyses show general agreement, with CLAES tending to be cooler by about $2 \mathrm{~K}$, except in the tropics and high-latitude winter conditions. This is supported by comparisons with individual radiosondes and several lidars that indicate that the agreement is within $2 \mathrm{~K}$ throughout the profile (except for a narrow layer around $3 \mathrm{mbar}$ ). An error analysis also indicates that systematic errors should be roughly $2 \mathrm{~K}$, independent of altitude. The systematic differences at low latitudes appear to be due to tropical waves, which have vertical wavelengths too short to be seen by the TIROS Operational Vertical Sounder (TOVS) instruments. There are no correlative rocketsondes or lidars to help resolve the reasons for the high-latitude differences. Comparisons with other Upper Atmosphere Research Satellite (UARS) data should shed additional light on this question.
\end{abstract}

\section{Introduction}

The Cryogenic Limb Array Etalon Spectrometer (CLAES) was launched on the NASA Upper Atmosphere Research Satellite (UARS) on September 12, 1991, and began measurements of the infrared radiation emerging from the atmospheric limb, or horizon, on October 1, 1991. The observed data included measurements of the radiation emitted by the $792 \mathrm{~cm}^{-1} Q$ branch of $\mathrm{CO}_{2}$ as a function of relative altitude, from which the atmospheric temperature has been determined. The stored cryogen capacity of CLAES was designed to allow an 18-month lifetime on orbit. It actually operated for 19 months, acquiring 470 days of data, of which 388 (between January 9, 1992, and May 5, 1993) have been processed to date using version 7 (V7) data processing software. (Data acquired prior to January 9 measured slightly different wavelengths and will require a modified algorithm.) A V7 day file contains approximately 1200 altitude profiles each of temperature, aerosol extinction coefficient, and the mixing ratios of 11 species.

\footnotetext{
INational Center for Atmospheric Research, Boulder, Colorado. ${ }^{2}$ Lockhecd Palo Alto Rescarch Laboratory. Palo Alto. Calıfornia. ${ }^{3}$ Hughes STX Corporation, Lanham, Maryland.

${ }^{4}$ Service d'Aéronomic du CNRS, Vérricres-Le Buisson, France. ${ }^{5}$ Climate Analysis Center, NMC/NWS/NOAA, Washington, D. C. 6NASA Goddard Space Flight Center, Greenbelt, Maryland.

7Jet Propulsion Laboratory, California Institute of Technology, Pasadena.
}

Copyright 1996 by the American Geophysical Union.

Paper number 96JD00052.

0148-0227/96/96JD-00052\$05.00
This paper is concemed with the assessment of the quality of the CLAES-retrieved temperatures through error analysis, analysis of the data fields, and their comparison with correlative data. We give here a summary of those instrument design and operational characteristics most relevant to this assessment. Details of the instrument design and on-orbit performance can be found in the work of Roche et al. [1993], hereinafter referred to as R93, and a discussion of the UARS mission is given by Reber [1993] and Reber et al. [1993].

Temperature is the principal quantity defining the state of the atmosphere, determining its vertical structure. From a knowledge of the atmospheric temperature distribution, along with the pressure at one level, one may compute the distribution of atmospheric density and the pressure at all levels. From the pressure distribution, one can further calculate a good estimate of the extratropical winds.

In addition to its importance as a thermodynamic and dynamic variable, the temperature must also be known to invert the other radiance measurements in order to recover the vertical distributions of aerosols and trace gases. Clearly the importance of atmospheric temperature requires that the characteristics of the CLAES temperature determinations be accurately known.

\section{CLAES Temperature Determination}

\subsection{Observational Technique}

CLAES is a limb-viewing spectrometer, simultaneously observing infrared emission from the atmosphere with a vertical linear array of 20 abutting detectors, each subtending $2.5 \mathrm{~km}$ vertical height at the limb, viewing tangent altitudes nominally between 10 and $60 \mathrm{~km}$. CLAES views in a direc- 
tion perpendicular to the UARS velocity vector, from the side of the spacecraft opposite to the solar array (the "cold side"). As the UARS orbit precesses, it is necessary to rotate the spacecraft about the yaw axis approximately every 36 days to keep the solar panels pointing toward the Sun. This yawaround of UARS means that CLAES altemately observes from $34^{\circ} \mathrm{N}$ to $80^{\circ} \mathrm{S}$ or from $34^{\circ} \mathrm{S}$ to $80^{\circ} \mathrm{N}$, depending on the orientation of UARS. Because it measures thermal emission, data may be obtained at all local times, day and night, i.e., irrespective of whether the observed atmosphere is sunlit or dark. Each observed latitude is sampled about 15 times per day from the ascending (south to north) part of the orbit and likewise from the descending part of the orbit. Combining the observations from the two parts of the orbit over the 36-day yaw period provides coverage of a large fraction of the diumal cycle at a given latitude.

To prolong the life of the stored cryogens, the instrument aperture door was closed for approximately 5 days around the time of each spacecraft yaw. The telescope door carries on its inside surface a blackbody calibration source which was used for end-to-end radiometric calibration during the yawmaneuver door closings. The door was also closed for 1 to 2 days halfway between the yaws (roughly every 2 weeks) for additional radiometric calibration.

While viewing the atmosphere, CLAES was operated for the most part ( $\approx 94 \%$ of the time) in the nominal science mode (designated mode 1). In this mode, Earth-limb radiance data were obtained by sequentially positioning each of the nine blocker filters in the beam to isolate spectral regions a few inverse centimeters wide and spectrally scanning these regions by tilting an etalon in the beam (see R93 for details). These data allow retrieval of the entire CLAES species set, including temperature, $\mathrm{O}_{3}, \mathrm{ClONO}_{2}, \mathrm{HNO}_{3}, \mathrm{CFC}-11, \mathrm{CFC}-12$, $\mathrm{N}_{2} \mathrm{O}_{5}, \mathrm{~N}_{2} \mathrm{O}, \mathrm{CH}_{4}, \mathrm{NO}_{2}, \mathrm{H}_{2} \mathrm{O}, \mathrm{NO}$, and aerosol. Data were obtained with a UARS standard 65 -s repeat time, corresponding to about $500 \mathrm{~km}$ along the ground track. A given blocker was in place an average of about $7.2 \mathrm{~s}$. Because the blocker width was roughly 20 to 30 times the full width at half maximum (FWHM) of the etalon [James et al., 1988], there was not enough time for a continuous scan through the entire blocker region at etalon resolution. Instead, for each blocker region, the etalon was driven sequentially to a set of tilt angles that provided high-resolution measurements in a subset of frequencies, i.e., channels, selected to optimize information content for retrieval purposes. Typically, some of these channels would include the line centers of species to be retrieved and some would be located between lines in order to simultaneously retrieve aerosols or other continuum-emitting species.

\subsection{Temperature and Pressure Determination}

As a limb-viewing infrared spectrometer, CLAES temperature retrievals rely on the principles described by Gille and House [1971] (hereinafter referred to as GH), and used by several subsequent infrared limb scanners. For a gas with a known distribution, such as $\mathrm{CO}_{2}$, the infrared emission at a given altitude depends on the temperature and density at that altitude. The transmittance between that level and space depends on the density of the absorber and its temperature. The density at any level depends, through the hydrostatic equation, on the temperature distribution between the level in question and a reference level at which the pressure is known. Thus the temperature distribution and the pressure at a single known level are sufficient to determine the outgoing radiance profile.

Conversely, to retrieve the temperature, measurements of a radiance profile and knowledge of a single reference pressure are sufficient to determine the temperature distribution, as noted by $\mathrm{GH}$ (although more emphasis was placed there on the use of two radiometric channels to determine the temperature and the pressure simultaneously).

CLAES blocker filter 8 was selected to isolate a spectral region about $4 \mathrm{~cm}^{-1}$ wide centered near the $\mathrm{CO}_{2} Q$ branch at approximately $792 \mathrm{~cm}^{-1}$ for temperature retrieval. Figure 1 shows a calculated spectrum of atmospheric radiance at an altitude of $25 \mathrm{~km}$ in the blocker-8 region as it would be measured by CLAES. This can be done by tilting the etalon in a smooth motion to scan its passband continuously across the spectral region passed by the blocker- 8 filter. The large peak, at $791.7 \mathrm{~cm}^{-1}$ is the $Q$ branch of the second hot band of the $\mathrm{CO}_{2}$ principle isotope (626) $v_{2}$ system, often designated (11101-10002), which is used in the temperature determinations discussed here. The $\mathrm{CO}_{2}$ feature is the strongest in this blocker region. The weaker features at lower frequencies are ozone lines. (The small features in the aerosol signal are due to absorption of aerosol emission by the gases.) Because of the instrument finite field of view the FWHM of the

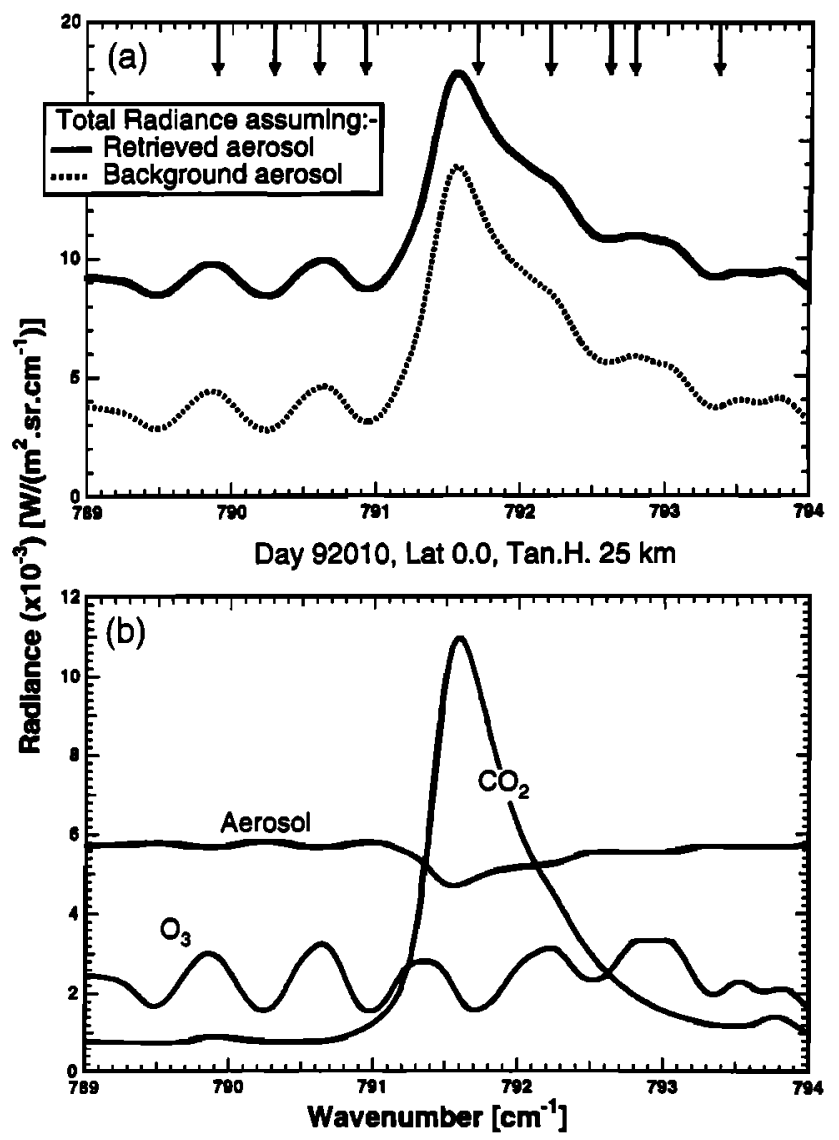

Figure 1. Calculated radiance spectra at $25 \mathrm{~km}$ altitude over the equator for January 10, 1992. (a) Solid line shows calculated total signal, using the retrieved amount of aerosol, compared with the same calculation with background aerosol (dotted line). Arrows indicate discrete etalon positions (frequencies or channels) at which mode-1 measurements are made. (b) Contributions to the solid line in Figure 1a, showing $\mathrm{CO}_{2}$ and $\mathrm{O}_{3}$ features, and the quasi-continuum of aerosol. 
spectral response broadens as a function of tilt angle $\theta$, from $0.245 \mathrm{~cm}^{-1}$ at normal incidence to $0.333 \mathrm{~cm}^{-1}$ at the largest angle involved. The central frequencies at which the outgoing radiance is measured in the science mode are indicated and given in Table 1.

The vertical distribution of radiances measured in the $791.70 \mathrm{~cm}^{-1} Q$-branch peak channel for a tropical atmosphere is shown in Figure 2. The signal varies by 2 orders of magnitude from bottom to top, mainly reflecting the decreasing density of the atmosphere and increasing transparency with altitude. Within the passband of the etalon the signal varies from $3 \times 10^{-6} \mathrm{~W} /\left(\mathrm{m}^{2} \mathrm{sr} \mathrm{cm}^{-1}\right.$ ) (denoted spectral radiance units (SRU) below) at the lowest level to $2 \times 10^{-8}$ SRU at the top. Even at the top the signal is 10 times greater than the quoted noise values of $1.4 \times 10^{-9} \mathrm{SRU}$.

The bulge between $20 \mathrm{~km}$ and $25 \mathrm{~km}$ is due to the effects of the heavy aerosol loading following the eruption of Mount Pinatubo. This plot also shows calculated estimates of maximum and minimum radiance in the tropics, based on temperatures and ozone amounts from the UARS climatology (developed by R. R. Seals and D. J. Wuebbles for the UARS Science Team; a description provided by P. S. Connell is given by Kumer et al. [1993]) and aerosols measured by SAGE. The radiance profile lies within or slightly over the estimated limits over the full altitude range, suggesting that there are no severe anomalies in the radiance measurements and their calibration, or in the calculations.

A research approach to solution of this multichannel, multiemitter retrieval from simulated CLAES data for ozone, temperature and pressure, and sensitivities to instrument effects, has been published by Kumer and Mergenthaler [1991]. The V7 production approach [Kumer et al., this issue] is similar in that it breaks the problem into the equivalent of a single-emitter and single-channel problem for each species by using a linear least squares approach for fitting calculated spectra to the observed data. In this case, the species are aerosol, ozone, and $\mathrm{CO}_{2}$ Following $\mathrm{GH}$, the $\mathrm{CO}_{2}$ distribution is assumed to be known so the equivalent single-emitter and single-channel formulation for $\mathrm{CO}_{2}$ can be used to retrieve temperature.

As noted above, knowledge of a single reference pressure is required. Spacecraft ephemeris and attitude data are used to calculate the geographic location and altitude viewed by each detector. The reference pressure is adjusted so that the mean CLAES-retrieved temperature is equal to that from the U.S.
National Meteorological Center (NMC) analysis for the pressure range of 100 to 10 mbar. How well this is accomplished is discussed below. The equivalent single-emitter and singlechannel retrievals and error estimation for each species are implemented by an approach [Kumer et al., this issue] similar to the Newtonian iterative algorithm [Rodgers, 1976, equation (99)]. For production data processing, the method requires a computationally efficient algorithm for calculation of radiance profiles. The model described by Marshall et al. [1994] is used for this purpose. The method uses initial guess ozone profiles from the UARS prelaunch climatology. NMC provides the initial guess temperature profile. The quality of CLAES-retrieved ozone data is the subject of a companion paper [Bailey et al., this issue]. Retrieved aerosol has been discussed in numerous papers [Mergenthaler et al., 1993; Roche et al., 1994; Massie et al., 1994]; its validation is also discussed in a companion paper [Massie et al., this issue.]

\section{Estimation of CLAES Experiment Systematic and Random Errors}

It is useful to compare the empirically estimated instrument systematic and random errors with the equivalent quantities inferred from correlative data comparisons and observed variability. In estimating instrument errors associated with the retrieval of temperature, the predicted errors in the measured and calculated atmospheric spectral radiances were applied to an altitude-dependent profile relating error in temperature to percent radiance error. This latter relationship was found empirically by using the retrieval algorithm to determine the sensitivity of the retrieved temperature to changes in the input radiance. The following paragraphs describe the components of the error estimation and summarize the total systematic and random errors for selected pressure levels for temperature in Tables 2 and 3, respectively.

\subsection{Systematic Errors}

The primary sources of systematic error are as follows:

Radiometric calibration. Atmospheric radiances are calibrated using the onboard blackbody calibration source (OBCS). Determination of spectral radiances from this source involves biases in the OBCS temperature as determined from five platinum resistance thermometers (PRTs), errors in the knowledge of the absolute emissivity, offsets in the electronic

Table 1. Narrowband channels used in the CLAES Blocker-8 Spectral Region for Retrieval of Temperature, Aerosol, and Ozone

\begin{tabular}{lll}
\hline Tilt Angle, deg & Spectral Position, $\mathrm{cm}^{-1}$ & \multicolumn{1}{c}{ Spectral Feature } \\
\hline 16.540 & 789.90 & $\mathrm{O}_{3}$ line center, i.e., peak \\
17.650 & 790.29 & minimum, i.e., in between lines, use for aerosol retrieval \\
18.679 & 790.60 & $\mathrm{O}_{3}$ line center, i.e., peak \\
19.450 & 790.92 & minimum, i.e., in between lines, use for aerosol retrieval \\
21.352 & 791.70 & strongest region of $\mathrm{CO}_{2} Q$ branch and overlapping $\mathrm{O}_{3}$ line \\
22.487 & 792.20 & slightly weaker region of $\mathrm{CO}_{2} Q$ branch \\
$5.460^{*}$ & 792.61 & progressively weaker region of $\mathrm{CO}_{2} Q$ branch, and $\mathrm{O}_{3}$ \\
$6.674^{*}$ & 792.78 & $\mathrm{CO}_{2}$ and $\mathrm{O}_{3}$ \\
$9.926^{*}$ & 793.36 & $\mathrm{CO}_{2}$ and aerosol \\
\hline
\end{tabular}

\footnotetext{
* These channels use the next order etalon transmission feature.
} 


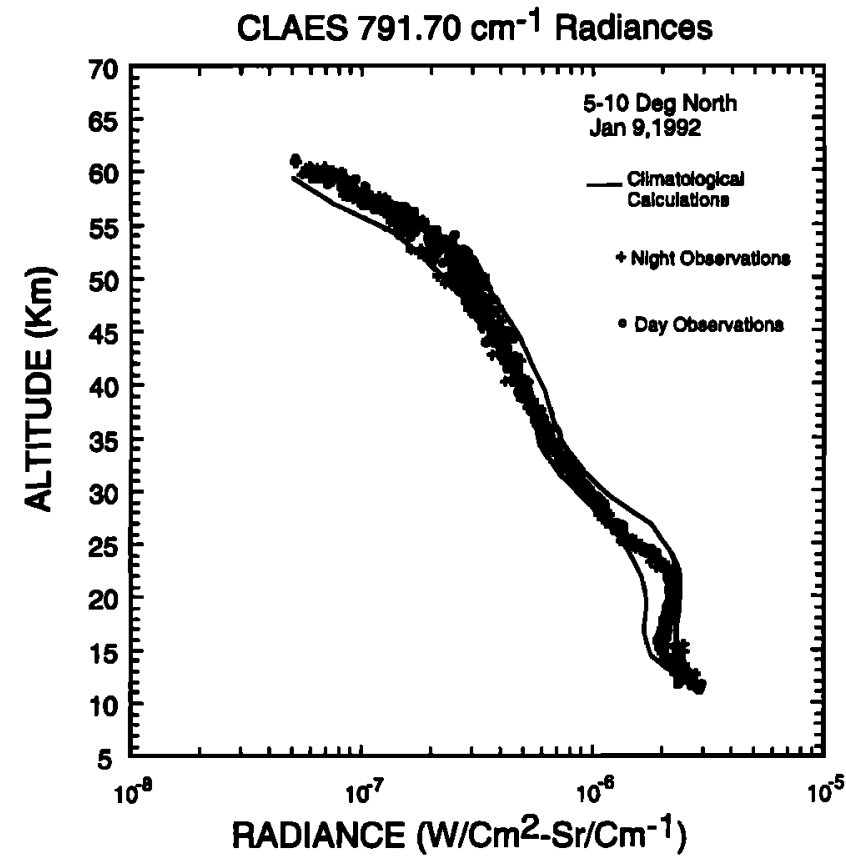

Figure 2. Observed radiances in the $791.7-\mathrm{cm}^{-1}$ channel from the 20 detectors (symbols) versus altitude between $5^{\circ}$ and $10^{\circ} \mathrm{N}$, on January 10,1992 , compared to calculations based on UARS climatological maxima and minima of ozone and aerosol, and NMC temperatures. (Pluses are night; open circles are day observations.)

zero-photon level, uncertainty in foreoptics thermal emission, and the use of a detector "characteristic responsivity curve" fitting technique to provide responsivities for atmospheric radiances below the minimum (coldest) OBCS radiance. The design and prelaunch characterization of the OBCS has been discussed by Sterritt et al. [1990]. OBCS temperature and emissivity uncertainties in the $790-\mathrm{cm}^{-1}$ spectral channel amount to approximately $1.1 \%$ root-mean-square (RMS) radiance error at the OBCS coldest temperature of $160 \mathrm{~K}$. The other uncertainties listed above are mainly of interest in this wavelength region for high-altitude, low-radiance conditions. The root-sum-square (RSS) of all systematic radiometric calibration radiance errors is estimated to be in the range 1.1$2.5 \%$ between 100 and 0.46 mbar. For the V7 software used in the retrieval of the data discussed here, only calibrations up to August 10, 1992, were used. This leaves a roughly linear responsivity trend of about $3 \%$ in the $790-\mathrm{cm}^{-1}$ channel from August 10,1992, to January 15, 1993, followed by recovery to the August 10,1992, value by April 24, 1993, as the detector temperature increase accelerated toward the end of the cryogen lifetime. This small trend will be removed in future software versions. We also note that during the last six days of the mission, April 30, 1993, through May 5, 1993, the detector temperature was rising very rapidly, with associated rapid changes in responsivity and noise. The V7 data for this period therefore should be used with considerable caution. Special calibration software will be developed to improve the quality of data from these six days.

Instrument characterization. This includes absolute wavelength calibration, spectral transmission function, spectral dispersion along the vertical extent of the array, detector spatial responsivity, optics out-of-field stray light rejection, and in-field scattering (optical cross talk). James et al. [1988] discuss the design and prelaunch characterization of the CLAES solid Fabry-Perot etalons, and Mergenthaler et al. [1990], and Kumer et al. [1990] discuss aspects of the design and prelaunch characterization of the blocking filters. Information on the absolute wavelength calibration and the effective spectral transmission function can also be deduced from onorbit spectral scans of specific emission features, and limits on off-axis and in-field scattering can be deduced on orbit from high altitude and "cold space" radiance measurements. From prelaunch and on-orbit analysis we estimate an uncertainty of $0.01 \mathrm{~cm}^{-1}$ both in the absolute spectral calibration and in the spectral function width. The spectral calibration error results in a relatively small radiance error of $0.6 \%$. The uncertainty in the spectral function, however, represents a $3 \%$ error at median tilt angles in the $790 \mathrm{~cm}^{-1}$ etalon spectral function. The error has some covariance between the measurement of atmospheric spectra and the measurement of the nearly continuum-like radiance from the $\mathrm{OBCS}$, especially for quasi-continuum atmospheric emitters such as aerosol and $\mathrm{CFCl}_{3}$, and in the wings of overlapping lines. This would tend to reduce the effective radiance error associated with the spectral function uncertainty in these situations. However, for the purposes of comparing estimated systematic error with that inferred from correlative measurements in this paper we will assume the maximum 3\% radiance error. Array dispersion effects contribute less than $1.2 \%$ radiance error, and detector uniformity contributes less than $0.5 \%$. Array cross talk contributes less than $1 \%$ from 100 to 0.46 mbar. The RSS of all instrument characterization radiance uncertainties is estimated to be in the range $3.1-3.3 \%$ between 100 and 0.46 mbar.

Table 2. Contribution to Systematic Temperature Error

Systematic Temperature Error, $\mathbf{K}$

\begin{tabular}{ccccc}
\hline $\begin{array}{c}100 \mathrm{mbar} \\
(16.00 \mathrm{~km})\end{array}$ & $\begin{array}{c}46 \mathrm{mbar} \\
(21.40 \mathrm{~km})\end{array}$ & $\begin{array}{c}10 \mathrm{mbar} \\
(32.00 \mathrm{~km})\end{array}$ & $\begin{array}{c}1.0 \mathrm{mbar} \\
(48.00 \mathrm{~km})\end{array}$ & $\begin{array}{c}0.46 \mathrm{mbar} \\
(53.40 \mathrm{~km})\end{array}$ \\
\hline 0.45 & 0.49 & 0.52 & 1.19 & 0.99 \\
0.27 & 0.29 & 0.31 & 0.32 & 0.26 \\
1.26 & 1.38 & 1.44 & 1.50 & 1.20 \\
0.42 & 0.55 & 0.43 & 0.15 & 0.04 \\
0.04 & 0.04 & 0.14 & 0.06 & 0.14 \\
0.08 & 0.09 & 0.10 & 0.20 & 0.40 \\
1.26 & 1.38 & 1.44 & 1.50 & 1.20 \\
0.42 & 0.46 & 0.48 & 0.50 & 0.40 \\
1.95 & 2.16 & 2.23 & 2.52 & 2.07 \\
\hline
\end{tabular}


Table 3. Contribution to Random Temperature Error

\begin{tabular}{lccccc}
\hline & \multicolumn{5}{c}{ Random Temperature Errorr, K } \\
\cline { 2 - 6 } & $\begin{array}{c}100 \mathrm{mbar} \\
(16.00 \mathrm{~km})\end{array}$ & $\begin{array}{c}46 \mathrm{mbar} \\
(21.40 \mathrm{~km})\end{array}$ & $\begin{array}{c}10 \mathrm{mbar} \\
(32.00 \mathrm{~km})\end{array}$ & $\begin{array}{c}1.0 \mathrm{mbar} \\
(48.00 \mathrm{~km})\end{array}$ & $\begin{array}{c}0.46 \mathrm{mbar} \\
(53.40 \mathrm{~km})\end{array}$ \\
\hline Radiometric calibration & 0.45 & 0.49 & 0.51 & 0.53 & 0.42 \\
Spectral calibration & 0.42 & 0.46 & 0.48 & 0.50 & 0.40 \\
Horizontal gradients & 0.42 & 0.46 & 0.48 & 0.50 & 0.40 \\
Vertical smear & 0.05 & 0.05 & 0.19 & 0.08 & 0.19 \\
Noise & 0.02 & 0.03 & 0.07 & 0.20 & 0.22 \\
Jitter & 0.50 & 0.91 & 0.92 & 1.77 & 2.03 \\
RSS of random errors & 0.90 & 1.22 & 1.27 & 1.99 & 2.17 \\
\hline
\end{tabular}

Spectral parameters. This involves a priori knowledge of spectral line strengths, shapes and positions, and their pressure and temperature dependencies, and knowledge of absorption cross sections for continua-like features. Spectral parameters are taken from the HITRAN92 compilation. For temperature the largest enror source is associated with the line strength uncertainty, for which we chose $\pm 3 \%$ [Rothman et al., 1992; Johns, 1992].

Forward radiance model. This primarily involves radiative transfer approximations, treatment of line overlap and mixing, and calculation of emissivity growth approximation (EGA) table coefficients. Errors estimated by comparing the forward model results with rigorous line-by-line code calculations show that the average systematic radiance error is about $1 \%$.

Table 2 summarizes the systematic error estimates in retrieved temperature from these various radiance effects for five pressure levels. The estimated systematic errors in temperature are dominated by uncertainties in spectral parameters and the spectral response function. The estimated systematic errors, obtained by taking the RSS of the individual components, are found to be between 1.95 and $2.52 \mathrm{~K}$. These values are to be compared with those found in sections 5 and 6 .

\subsection{Random Errors}

The primary sources of random error are as follows:

Spectral Repeatability. The primary instrument contributors to random errors in the measured radiances involve repeatability in the angular (i.e., spectral) positioning of the Fabry-Perot etalons. Observed repeatability showed it to be better than $0.03^{\circ}$, and a similar value was inferred from observations of scatter in the shape of the on-orbit spectral modulation curves obtained during OBCS calibrations. For the $792-\mathrm{cm}^{-1}$ temperature channel this results in a random error of less than $1 \%$ in the measurement of atmospheric line radiances.

Horizontal gradients. Random errors due to line-of-sight gradients in the viewed radiances were investigated by looking at the sensitivity of the retrieval algorithm to induced gradients. This led to an estimate of approximately $1 \%$ equivalent radiance error. For these two mechanisms the radiance errors were converted to temperature errors in the same way as for the systematic errors and are presented in Table 3.

Radiometric Noise. Instrument radiance noise is characterized as the noise equivalent spectral radiance (NESR) in SRU units. This is defined as the input spectral radiance at the instrument aperture required to give an output signal equal to the system noise for a specific integration time. The NESR has a specific value for each of the 20 CLAES detectors and also for the specific spectral positions within each particular channel, due to the variation of the effective blocker filter transmission during a spectral scan. A measure of the effective NESR due to the instrument alone is obtained by looking at the variance of a large number of mode-1 measurements obtained when UARS was rolled, so that CLAES looked well above the sensibly emitting atmosphere into a region of very low radiances. Using the mode- 1 radiance ensures use of the identical spectral positions, dwell times, integration times, and gains as those used when viewing the atmosphere. Further, these rollup radiances are conditioned in an identical manner to those used in the retrieval of atmospheric parameters, particularly with respect to the reduction of a quasi-sinusoidal lowfrequency artifact ("ripple") seen in the electronics dark noise output. For the eight spectral positions used in the retrieval of species in the $790-\mathrm{cm}^{-1}$ channel the array average NESR as seen in the roll-up data lies between $0.8 \times 10^{-9}$ SRU and $1.4 \times 10^{-9}$ SRU.

Another measure of the NESR can be obtained from science mode measurements obtained during the cooldown of the OBCS. In this case, the signal levels are higher, and the noise levels are larger, indicating a value of about $5.0 \times 10^{-9} \mathrm{SRU}$. These signal levels are closer to those seen in the stratosphere, and the difference suggests that the noise depends, to some extent, on signal level. We might expect to see the higher noise levels associated with the atmospheric radiances going into the retrievals. We will use the higher value in this error discussion.

The effect of this noise was estimated by simulation, adding Gaussian random noise with the above magnitude to calculated radiances, and carrying out the retrieval. First, an ideal radiance profile was derived from a temperature profile. Radiometric noise with NESR of $5 \times 10^{-9}$ was added to each of the five channels. The radiance profile was inverted, and the resulting solution was compared with the initial profile. The RMS difference between a number of simulated profiles and the initial profile gives an estimate of the precision. Additional simulations showed that as expected, the precision estimates were not significantly affected by the initial profile chosen. The standard deviations of 10 cases are shown in Table 3. Noise errors lead to temperature errors that grow with altitude, as the signal-to-noise ratio decreases at higher altitudes.

Vertical jitter. During observations a combination of random error in the positioning of the limb acquisition and adjustment mirror (LAAM) and oscillatory spacecraft motions 
that are not well sampled by the standard 2.048 -s roll data, with a magnitude of several tens of meters of motion of the tangent point (R. J. Wells and C. D. Rodgers, unpublished study, 1994) contributes additional random noise to the retrievals. The thermal snap, occurring when the solar array passes between sunlight to shadow, also causes large altitude excursions that last for over a minute. This random vertical motion between etalon positions is estimated to be approximately $80 \mathrm{~m}$. The resulting error in temperature will depend on the vertical gradients of the channel radiances. Again, simulated $790-\mathrm{cm}^{-1}$ channel radiances were calculated, with random altitude errors between the etalon positions. The errors had a Gaussian distribution, with an amplitude of $80 \mathrm{~m}$. The RMS differences from the true values for 10 cases are shown in Table 3. Temperature errors due to jitter do not have a strong dependence on altitude.

The RSS of these values for these independent error sources are also shown in Table 3. In the next section these values will be compared to an observational determination of the precision of CLAES temperature retrievals.

\section{Observed Precision of CLAES Temperature Determinations}

The true temperature $T$ is related to the retrieved temperature $T_{R}$ by the expression

$$
T_{R}=T+\varepsilon_{A} \pm \varepsilon_{P}
$$

where $e_{A}$ and $e_{P}$ are the accuracy and precision associated with $T_{R}$. (Estimation of $e_{A}$ is discussed in sections 5 and 6.)

When the same area is viewed within a time period short enough to minimize atmospheric variability, the precision may be estimated directly from temperature profiles retrieved using the operational software. The CLAES limb-viewing track intersects itself at the northernmost and southernmost parts of the tracks $\left(80^{\circ} \mathrm{N}\right.$ and $32^{\circ} \mathrm{S}$ or $32^{\circ} \mathrm{N}$ and $80^{\circ} \mathrm{S}$ depending on the phase of the spacecraft yaw cycle). This feature enables nearly coincident profiles from successive orbits to be obtained at these latitudes. The profile pairs so obtained are separated in time by the orbital period of $96.4 \mathrm{~min}$ and are within $\pm 1^{\circ}$ latitude and $\pm 2^{\circ}$ longitude of each other.

Assuming that atmospheric and instrument characteristics remain unchanged (i.e., $T$ and $e_{A}$ are constant) over these spatial and temporal scales, the RMS difference between the pairs $T_{R_{1}}$ and $T_{R_{1}}$ gives a measure of the precision,

$$
\varepsilon_{P}=\sqrt{\left(\left|T_{R_{1}}-T_{R_{J}}\right|^{2}\right) / 2}
$$

where angle brackets indicate an average over the number of comparison pairs. This assumption does not hold exactly and this estimate for the precision should therefore be considered an upper limit for the true value.

Precision estimates were also calculated, based on simulations including both dominant noise sources, jitter and instrumental noise, with the magnitudes discussed in section 3.

Figure 3 compares the precisions calculated using large numbers of pairs of profiles at $32^{\circ} \mathrm{N}$ or $32^{\circ} \mathrm{S}$ during the two northern and one southern winter to the precisions derived using simulated radiances, plotted as a thick solid line. The

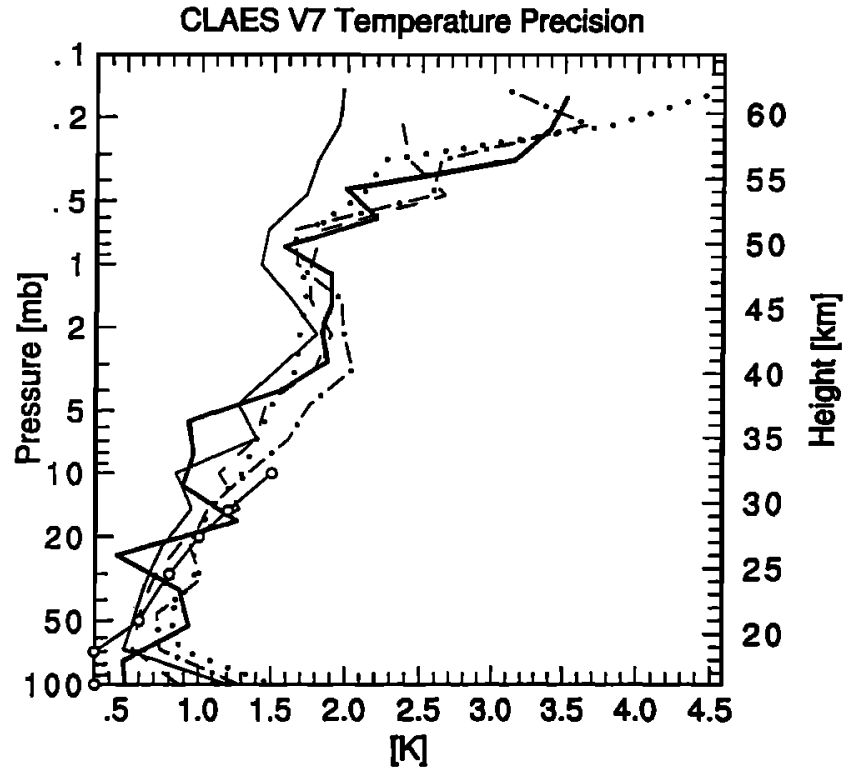

Figure 3. CLAES V7 temperature precision as a function of altitude. Empirical determinations (see text): thin solid line, January $9-12,1992,32^{\circ} \mathrm{S}, 53$ pairs; dashed, June 20-July 10 , $1992,32^{\circ} \mathrm{N}, 280$ pairs; dashed-dotted, July 30-August 10 , $1992,32^{\circ} \mathrm{S}, 160$ pairs; dotted, December 2, 1992, to January 7, $1993,32^{\circ} \mathrm{S}, 482$ pairs. The simulation is shown by the thick solid line. Radiosonde precision [Nash and Schmidlin, 1987] is indicated by the line connecting the open circles.

precisions calculated from the data all show the same increasing dependence on altitude, with similar values; the spread gives an idea of the variability of this estimate, which may also contain some component of atmospheric variability. These values are similar for all yaw periods. The simulated precision shows the same dependence on altitude, with similar values. In summary, precision values estimated by both methods are about $1 \mathrm{~K}$ in the lower stratosphere, less than $2 \mathrm{~K}$ up to the stratopause, and reach approximately $3.5 \mathrm{~K}$ in the lower mesosphere. The agreement between the two estimates supports the idea that random noise and jitter are the dominant factors contributing to the random temperature errors. Estimated radiosonde precisions [Nash and Schmidlin, 1987] are also shown; they are comparable to or larger than the observed CLAES precision values over the altitude range of $20-30 \mathrm{~km}$.

\section{Comparisons of CLAES Temperature Retrievals with Global Analyses}

\subsection{General Approach}

Ideally, CLAES retrievals would be compared to established, accepted measurement standards that were valid under all conditions and available in all locations, and appropriate error statistics developed. These estimates would then be compared to the calculated systematic errors in CLAES temperatures that were presented in section 3 to demonstrate that the sources of error were understood and properly quantified.

Unfortunately, assessment and verification of the accuracy of stratospheric quantities is difficult in any case because of the lack of such ideal standards. Estimating the accuracy of stratospheric temperature determinations is a different problem 
from that of other quantities because of the number of other methods and measurements available; it is also potentially more ambiguous, because these other methods do not always agree with each other as well as would be desired. Comparisons inevitably require attempts to discover which of the "standard" measurements is closest to the truth. In addition, space-based determinations bring their own set of difficulties, including differences of horizontal and vertical resolution and measurement time, from ground-based measurements as well as from each other.

CLAES data cover a large part of the globe every day and are expected to be used in a globally mapped form for many research applications. Comparisons show that temperatures determined on the ascending and descending (northward and southward) portions of the orbits are in good agreement, except in locations where the different orbital sections systematically sample different parts of the daily temperature cycle. Similar effects have been noted in temperatures retrieved by other instruments with the same view direction (e.g., MLS, E. Fishbein, personal communication, 1995). The following analyses combine all CLAES data.

The approach adopted here is to compare mapped CLAES temperatures with standard global analyses of stratospheric temperature. This will allow a determination of overall differences with CLAES. Such comparisons will also show the conditions under which there are large differences. It will then be possible to investigate those situations in greater detail, to see what can be learned about both types of data.

In particular, global analyses are operationally produced on a daily basis by NMC, for a series of pressure levels up to 0.4 mbar, based on temperatures measured by conventional balloon-borne radiosondes and those derived from the TOVS system on NOAA satellites [Gelman et al, 1994; Finger et al., 1993]. The NMC analyses use radiosonde data up through 10 mbar in the northern hemisphere $(\mathrm{NH})$, along with satellite data; above that, only satellite data are used. In the southern hemisphere (SH), where there are far fewer radiosondes, only satellite data are used above $100 \mathrm{mbar}$. The gridding employs a Cressman approach to use the observations to modify the initial field, which is analyzed TOVS data. The temperature corrections provided by Gelman et al. [1994] have been applied to the analyses used here. There are few independent data with which to evaluate systematic errors. They present a table of estimated combined random and systematic errors, with values ranging from $1.5 \mathrm{~K}$ at $100 \mathrm{mbar}$ in data rich areas to $7 \mathrm{~K}$ at $1 \mathrm{mbar}$ and $9 \mathrm{~K}$ at $0.4 \mathrm{mbar}$.

In addition, the United Kingdom Meteorological Office (UKMO), to support the UARS program, developed a data assimilation code to produce global analyses based on the same input data [Swinbank and O'Neill, 1994]. The UKMO analyses assimilate the radiosonde measurements and the TOVS satellite temperature retrievals into their model. Thus one would expect that the UKMO maps might be characterized by better vertical continuity and coherence, as well as perhaps better temporal continuity, than the NMC analyses. There are also differences in the screening techniques, which determine which data are retained in the analyses, which may influence analyses in extreme or rapidly changing conditions.

Because both of these analyses are based on TOVS retrievals, it is worth noting some points about them. The TOVS sounders [Smith et al., 1979] are cross-track nadir sounding instruments, with quite broad weighting functions, the high- est of which peaks near 2 mbar. Retrievals produce layer-mean temperatures between the standard levels used in the NMC analyses, which are spaced about $7 \mathrm{~km}$ apart. The temperatures at these levels are derived by log-linear interpolation between the given TOVS layer-mean temperatures. Thus their vertical resolution is coarse compared to that of CLAES. In addition, there is limited measurement information in the 0.4-mbar field.

The CLAES profiles have been mapped using a Kalman filter approach, similar to that described by Kohri [1981], but improved to allow more data to be included and imposing better latitudinal continuity. All sets of data were supplied at the UARS pressure levels, given by the expression $p(n)=$ $10^{n / 6}$ for integer $n$ in the range $12>n>-6$.

\subsection{Time-Latitude Cross Sections}

Figure $4 \mathrm{a}$ is a time versus latitude cross section plot of CLAES minus NMC zonal mean temperatures at 21.544 mbar. The alternating northward and southward viewing of CLAES resulting from the yaw-around of UARS can clearly be seen, as well as the data gaps resulting from closing the CLAES door. Note that at this level, temperature differences are generally small $(<3 \mathrm{~K}$ ), except for large negative values $(\mathrm{NMC} \approx 9 \mathrm{~K}$ warmer than CLAES) in high southern latitudes in southern winter, when temperatures are very cold. A corresponding difference is not seen in the $\mathrm{NH}$, although there appears to be more small-scale variability with latitude and time. Otherwise, we note that differences tend to be negative and that differences in the tropics vary from positive to negative in a regular way. The same features are seen at 46.4 and $10 \mathrm{mbar}$, but the $\mathrm{NH}$ differences show more rapid variations.

The corresponding plot, comparing CLAES to UKMO data, is shown in Figure 5a; this shows the same general features, but the differences in SH winter are smaller than in Figure $4 \mathrm{a}$, and largest $(\approx 5 \mathrm{~K})$ away from the pole. The smaller differences are likely due to the inclusion of radiosonde temperatures in the UKMO assimilation [see Manney et al., this issue]. There are more positive differences, notably in the equatorial region.

Differences between CLAES and NMC at 2.15 mbar are shown in Figure 4b. Once again, large differences are seen in June 1992, in the depths of the southern winter, where differences up to $16 \mathrm{~K}$ are seen; these have disappeared by August. However, comparably large differences are also seen in the northern polar winter (December) at this level. Again, CLAES is generally cooler than NMC, and there are large differences in the tropics that vary with season. Differences at higher levels are not presented because of the lack of information in the TOVS radiances makes retrievals at higher levels suspect. Other comparisons will be used to evaluate temperatures at high altitudes.

Figure $5 \mathrm{~b}$ displays the differences from the UKMO at the same level. The same qualitative features are seen as in Figure $4 \mathrm{~b}$, but again the differences are somewhat smaller, and there are more positive (CLAES warmer) regions.

\subsection{Latitude-Pressure Cross Sections}

To get additional insight into some of the situations in which there are large differences between CLAES and NMC or UKMO, we next look at latitude-altitude cross sections of these differences for particular dates. The cross section of differences from NMC for early August 1992, when CLAES was viewing the northern summer and low-latitude $\mathrm{SH}$, is shown 

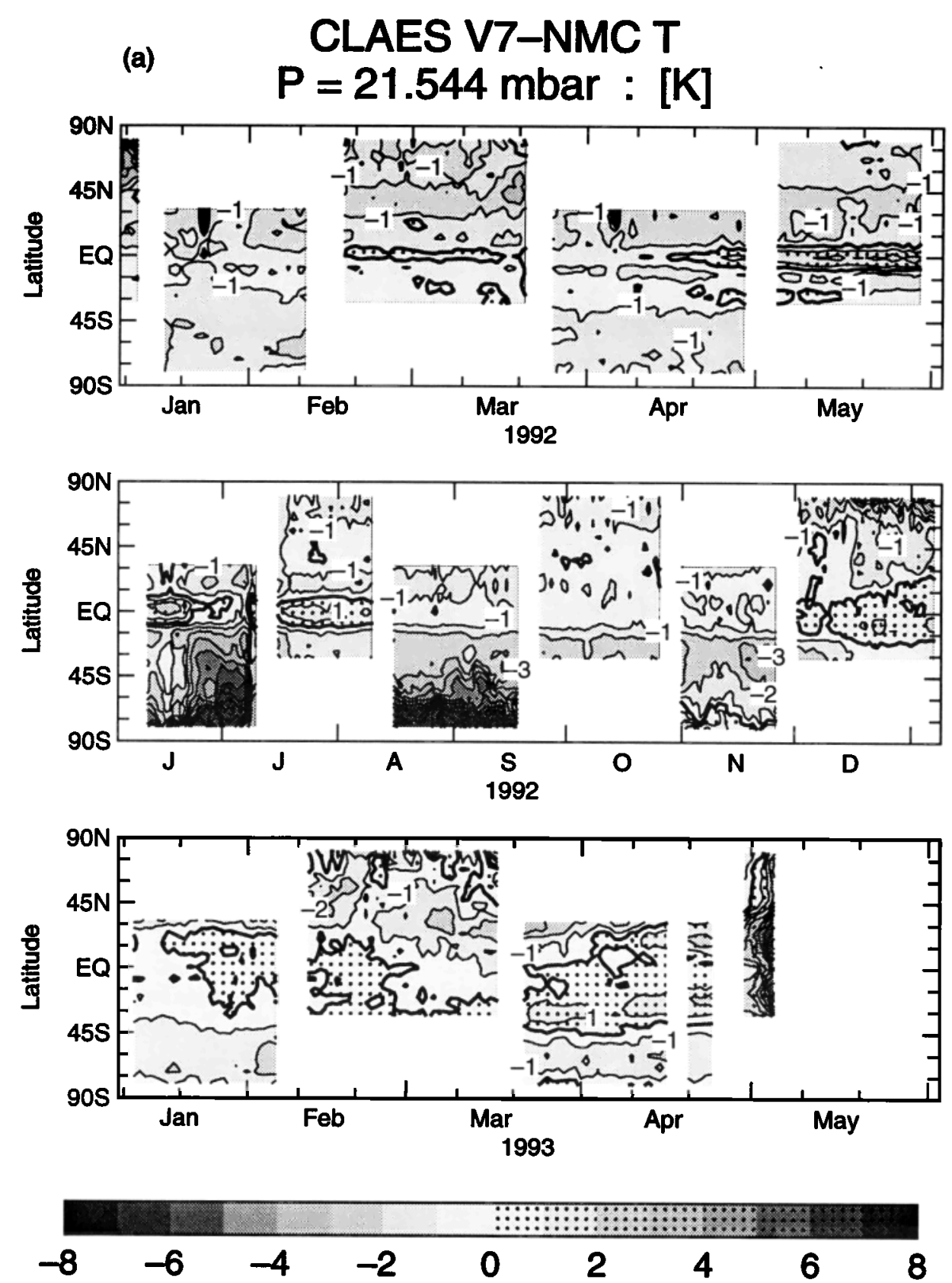

Figure 4. Time latitude plots of CLAES V7 minus NMC temperature: (a) 21.544-mbar surface; (b) 2.154-mbar surface.

in Figure 6a. Differences at most locations are small $(<2 \mathrm{~K})$, suggesting that under these conditions, when there are no extremes of temperature, the CLAES temperature retrievals give results in good agreement with the conventional data and the sources on which they are based.

However, there are differences of several degrees in the tropics, alternating in sign with altitude. These appear to be due to tropical waves, which have vertical wavelengths of only a few kilometers and are thus too small to be measured well with the conventional vertical sounding systems, which have vertical resolutions greater than $10 \mathrm{~km}$. These are discussed in more detail below.

There is also a smaller but significant difference (CLAES up to $4 \mathrm{~K}$ cooler than NMC) in a region from $45^{\circ} \mathrm{N}$ to $80^{\circ} \mathrm{N}$, between 2 and 3 mbar. Similar but slightly smaller differences are seen in comparisons with UKMO data (Figure 7a). However, the Microwave Limb Sounder (MLS) on UARS agrees with CLAES in this part of the atmosphere, which thus requires further attention.

A cross section for the June 1992 period, during the middle of the southern winter, is presented in Figure 6b, which shows much larger differences in the high-latitude $\mathrm{SH}$, centered at $65^{\circ}-70^{\circ} \mathrm{S}$, over a deep altitude region, as noted above. Given that the NMC analysis is based entirely on satellite data in this region of extremely cold temperatures, and have very broad weighting functions, it is not immediately clear which results are closest to the truth. However, the TOVS retrieval scheme, while physically based, relies on a priori information 

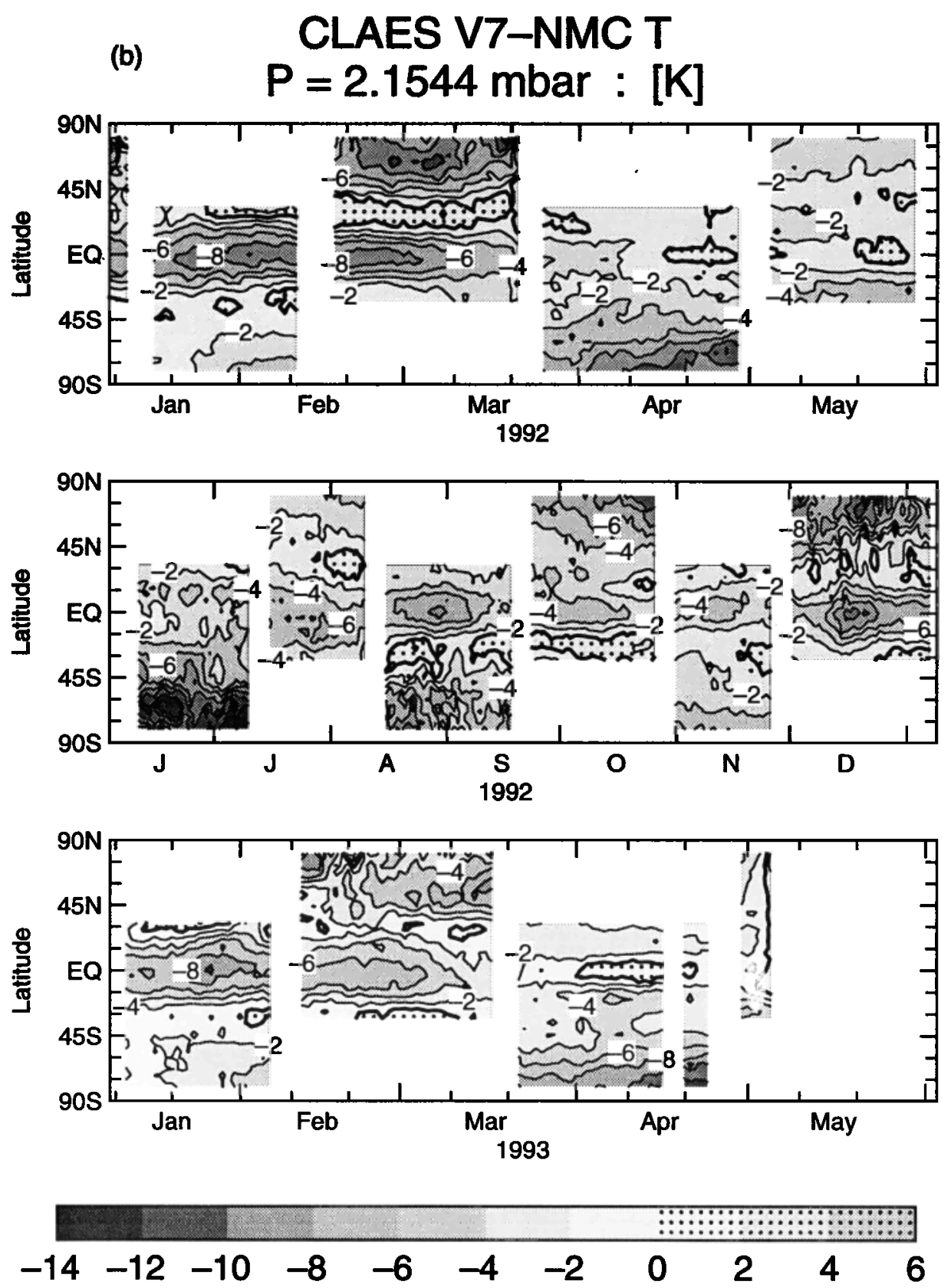

Figure 4. (continued)

derived from $\mathrm{NH}$ rocketsondes and radiosondes, which are warmer, and therefore will tend to provide a warm bias for the soundings.

The UKMO analyses employed in Figure $7 \mathrm{~b}$ incorporate radiosonde temperatures as well as the same satellite data; Figure $7 \mathrm{~b}$ shows the same features, which is not surprising, but with smaller differences. Clearly, this is another region to be looked at in more detail. Differences in the tropics are again smaller and consistent with the idea of tropical waves.

Cross sections for the two northern winter periods are presented in Figures $6 \mathrm{c}$ and $6 \mathrm{~d}$ for two days with comparable dates in 1992 and 1993, chosen for comparison by the UARS team. Again, there are large differences which vary strongly with altitude in the tropics. Of greater interest are the large differences at high latitudes. However, these differences with NMC are much greater than those with UKMO (Figures $7 \mathrm{c}$ and 7d) at both 30 and $40 \mathrm{~km}$ altitudes, and again MLS agrees with CLAES (and UKMO), suggesting that the NMC analyses may be too warm.

A further explanation may lie in the CLAES transmittances. In general, the agreement between the parameterized values and the detailed line-by-line calculations is better than $1 \%$, as given in section 3, but during the extreme cold of the Antarctic winter, errors of $4 \%$ occurred in the region of the temperature minimum, which could bias CLAES temperatures under extremely cold conditions. Based on these results, extra attention will be paid to the three situations of southern polar winter, northern polar winter, and variations in the tropics. 

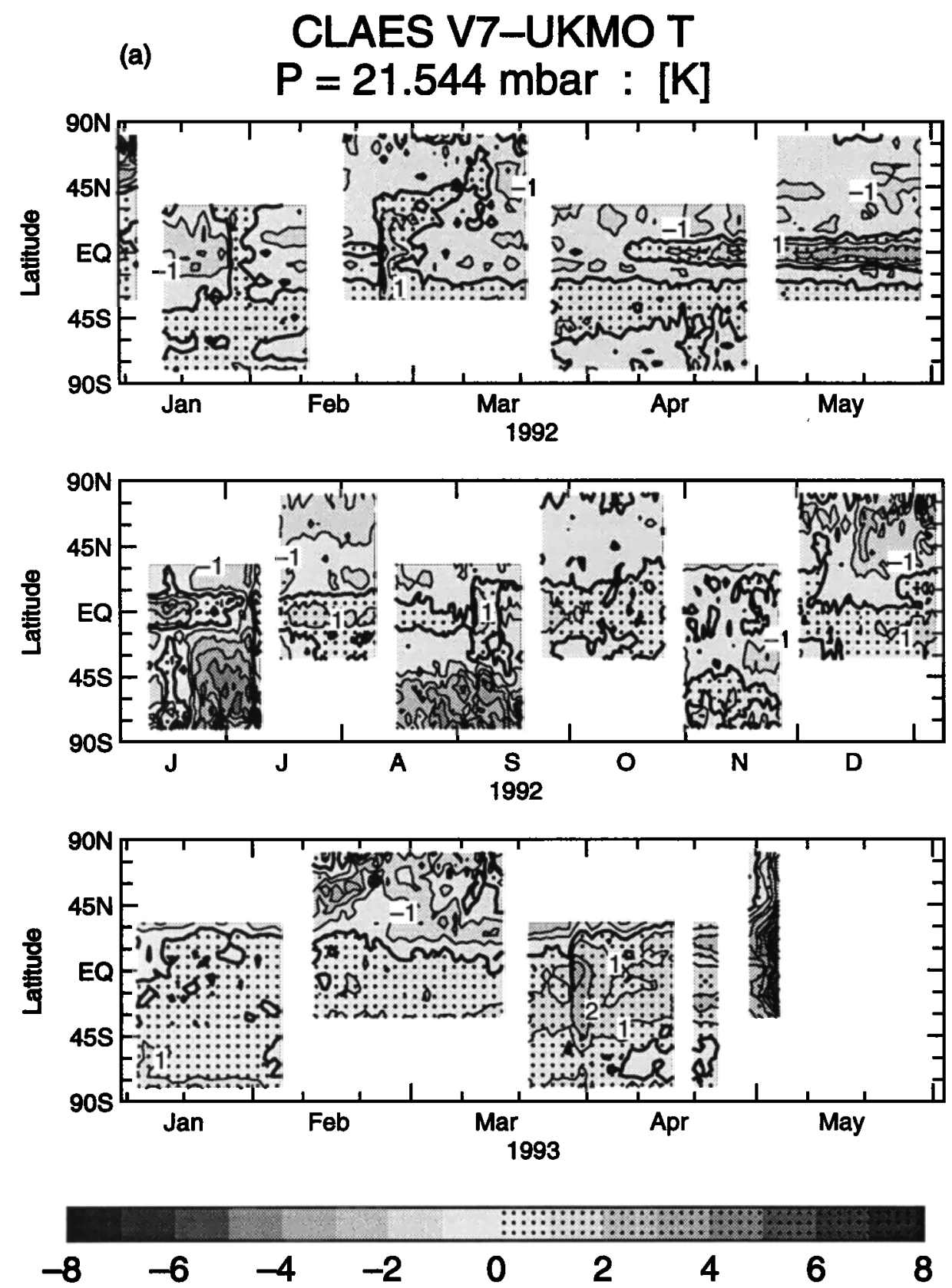

Figure 5. Time latitude plots of CLAES V7 minus UKMO temperature: (a) 21.544-mbar surface; (b) 2.154-mbar surface.

\section{Comparison of CLAES Temperatures with In Situ and Lidar Measurements}

As noted above, it is difficult to assess the absolute accuracy of satellite temperature determinations because of the lack of accepted temperature standards. The differences that may arise because the "overpasses" over the ground stations are not at exactly the same location or time as the ground-based measurements, and the larger volume sampled by the satellite instruments (compared to the local volumes sampled by the conventional data) also obscure the significance of observed differences. In addition, no single technique can cover the total altitude regime observed by CLAES. On the other hand, a ground-based (or ground launched) instrument can be carefully adjusted and calibrated before use, minimizing long-term drifts.

\subsection{Comparisons up to 10-mbar Pressure Level}

Radiosondes are launched, usually at 0000 and $1200 \mathrm{UT}$, from many locations in the NH and SH. Over 800 from each time reach the 70-mbar level, but the number decreases rapidly at the upper levels, such that only slightly over 100 reach the 10-mbar level, almost all in the NH (W. J. Randel, private communication, 1995).

Comparisons were made against standard meteorological radiosondes, provided by $\mathrm{NMC}$, in each of the comparison 
(b)
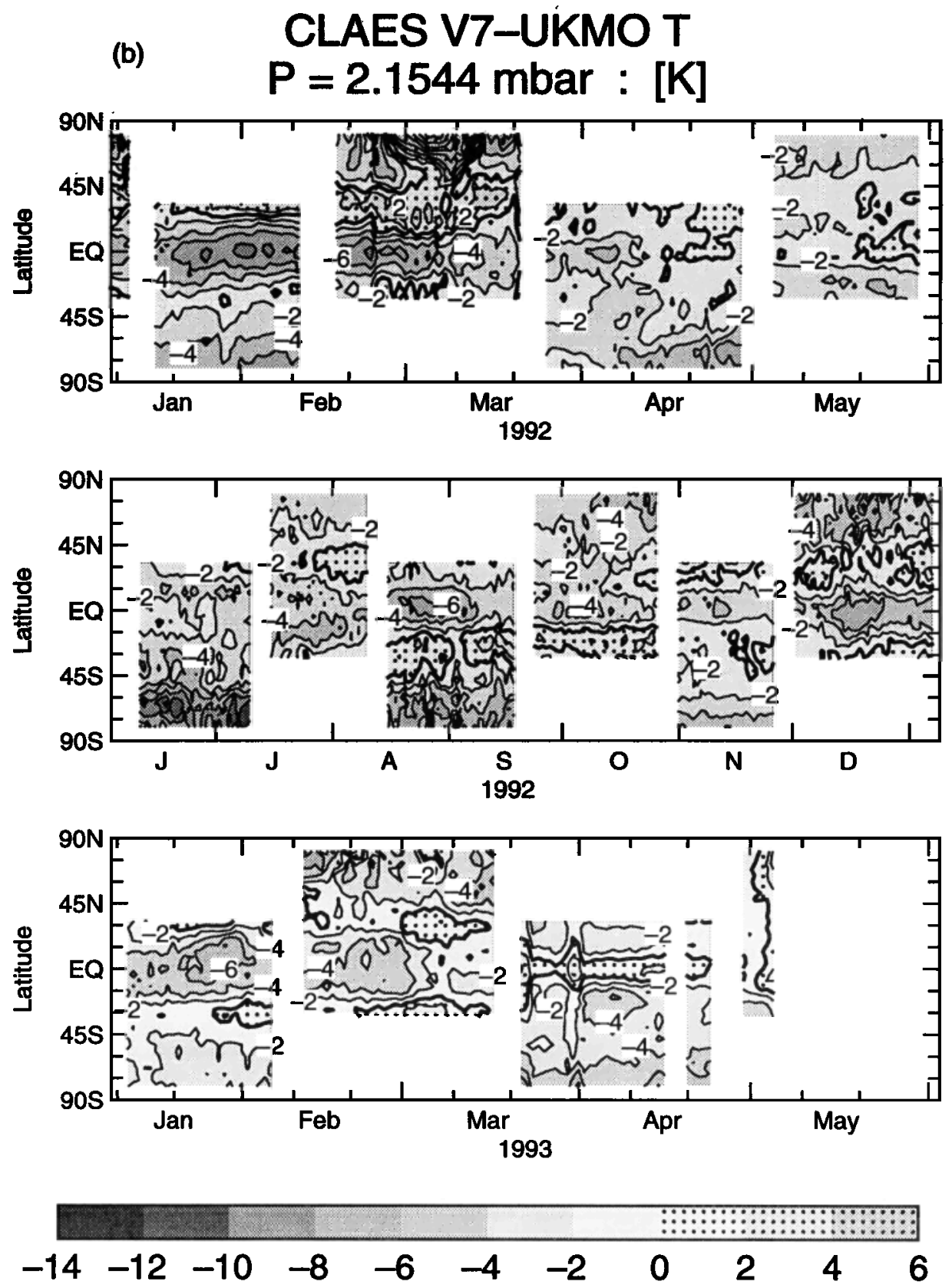

Figure 5. (continued)

periods. The coincidence criteria used for the radiosonde comparisons were $1^{\circ}$ latitude, $4^{\circ}$ in equivalent longitude ( $4 \%$ cosine (latitude)), or about $450 \mathrm{~km}$, and 3 hours. If more than one CLAES sounding met these criteria for a single radiosonde, all were included in calculating the statistics. For each pressure level the number of difference pairs that were used in computing the mean difference for that level was calculated. The maximum and minimum number of these difference pairs used in each comparison are given in the figure captions, in the form maximum/minimum. The mean differences along with the standard deviations of the mean $(\operatorname{SD}(\bar{x}))$ defined as

$$
\mathrm{SD}(\bar{x})=\sqrt{\sum_{i=1}^{N} \frac{\left(x_{i}-\bar{x}\right)^{2}}{N(N-1)}}
$$

were computed, either locally or in specific latitude bands.

Figure $8 \mathrm{a}$ presents the average CLAES minus radiosonde differences averaged over the globe, with their $\operatorname{SD}(\bar{x})$ values, for the undisturbed NH summer (August 8-11, 1992) situation mentioned above. Between 100 and 10 mbar CLAES retrievals are less than $2 \mathrm{~K}$ cooler than the radiosondes, with an $\operatorname{SD}(\bar{x})$ small enough to indicate that the differences are significant. The NMC-analyzed values at the radiosonde locations are also compared to the radiosonde values. As expected, the analyses and the radiosondes are in very good agreement. The results are essentially unchanged if the data are stratified by latitude. The mean differences provide quantitative values for the CLAES accuracies. One interpretation is that these are the characteristic accuracies of the temperature retrievals and that larger values in other situations result from special circumstances which can be identified. 

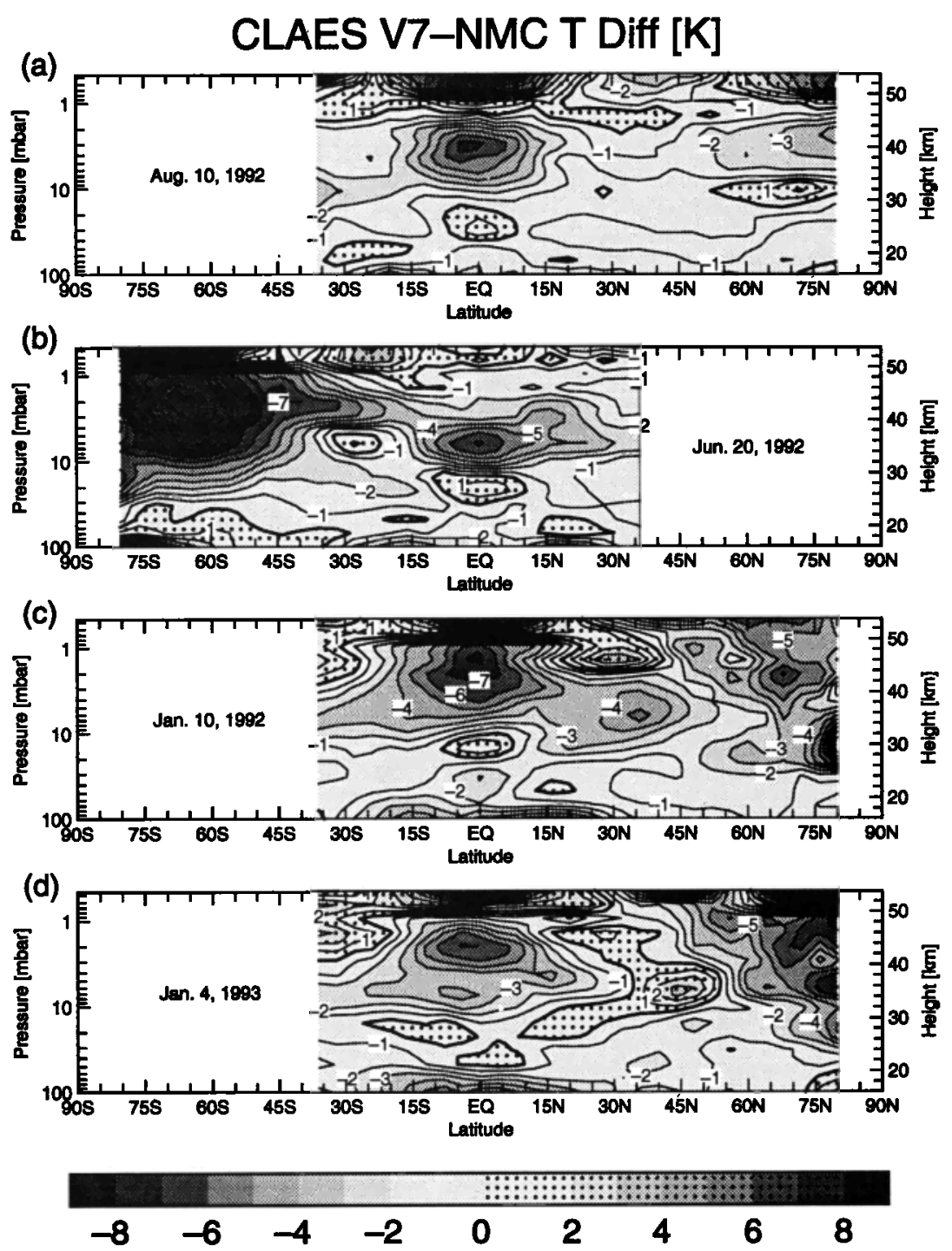

Figure 6. Latitude-pressure cross sections of CLAES V7 minus NMC temperature: (a) August 10, 1992; (b) June 20, 1992; (c) January 10, 1992; (d) January 4, 1993.

High-latitude differences, averaged over a yaw cycle are shown in Figure 8b, which also compares the NMC analysis with the radiosondes. The differences show a slightly different pattern, but the differences from the radiosondes are still less than or equal to $2 \mathrm{~K}$, and NMC is again in good agreement with the radiosondes for these conditions. However, individual shorter situations, such as January 9-11, 1992, show larger differences at 14 and 10 mbar (Figure 8c).

A different picture is presented in Figures $9 a$ and $9 b$, which shows that the CLAES retrievals averaged over a yaw period in the depths of the southern winter are lower than the radiosondes by up to $3 \mathrm{~K}$, while the NMC analyses are warmer than the radiosondes by up to $5 \mathrm{~K}$. The NMC minus radiosonde differences are largest in the $60^{\circ}-80^{\circ} \mathrm{S}$ latitude band. An obvious cause is the neglect of the radiosonde data in the SH stratospheric analyses. They probably result from several causes, including neglect of the radiosonde data in the SH stratospheric. In addition, although a physically based retrieval is used, it has characteristics of a regression scheme, and the retrievals are unable to get as cold as the extremes.

Because these are the coldest temperatures, it raises the question of whether there is a bias that causes CLAES to give low results when the temperature is cold. Plots of CLAES minus radiosonde at 21.5 mbar for the northern and southern hemispheres are presented in Figure 10. From December 2, 1992 , to January 7,1993 , in the $60^{\circ}-80^{\circ} \mathrm{N}$ band (Figure 10a) CLAES averages $1.2 \mathrm{~K}$ cooler than the radiosondes, but the mean difference becomes more negative below $195 \mathrm{~K}$, as indicated by a least squares fit (solid line). A similar but more extreme result, based on radiosondes between $40^{\circ}-80^{\circ} \mathrm{S}$ from June 11 to July 10,1992 (Figure 10b), shows CLAES cooler, on average, by $2.85 \mathrm{~K}$ but with larger curvature for the slightly lower temperatures observed by the radiosondes. In the NH (Figure 10a) the minimum difference is near $200 \mathrm{~K}$, and the fit difference at $190 \mathrm{~K}$ is about $2 \mathrm{~K}$, while in the $\mathrm{SH}$, the fit difference, for a differently distributed and much smaller num- 

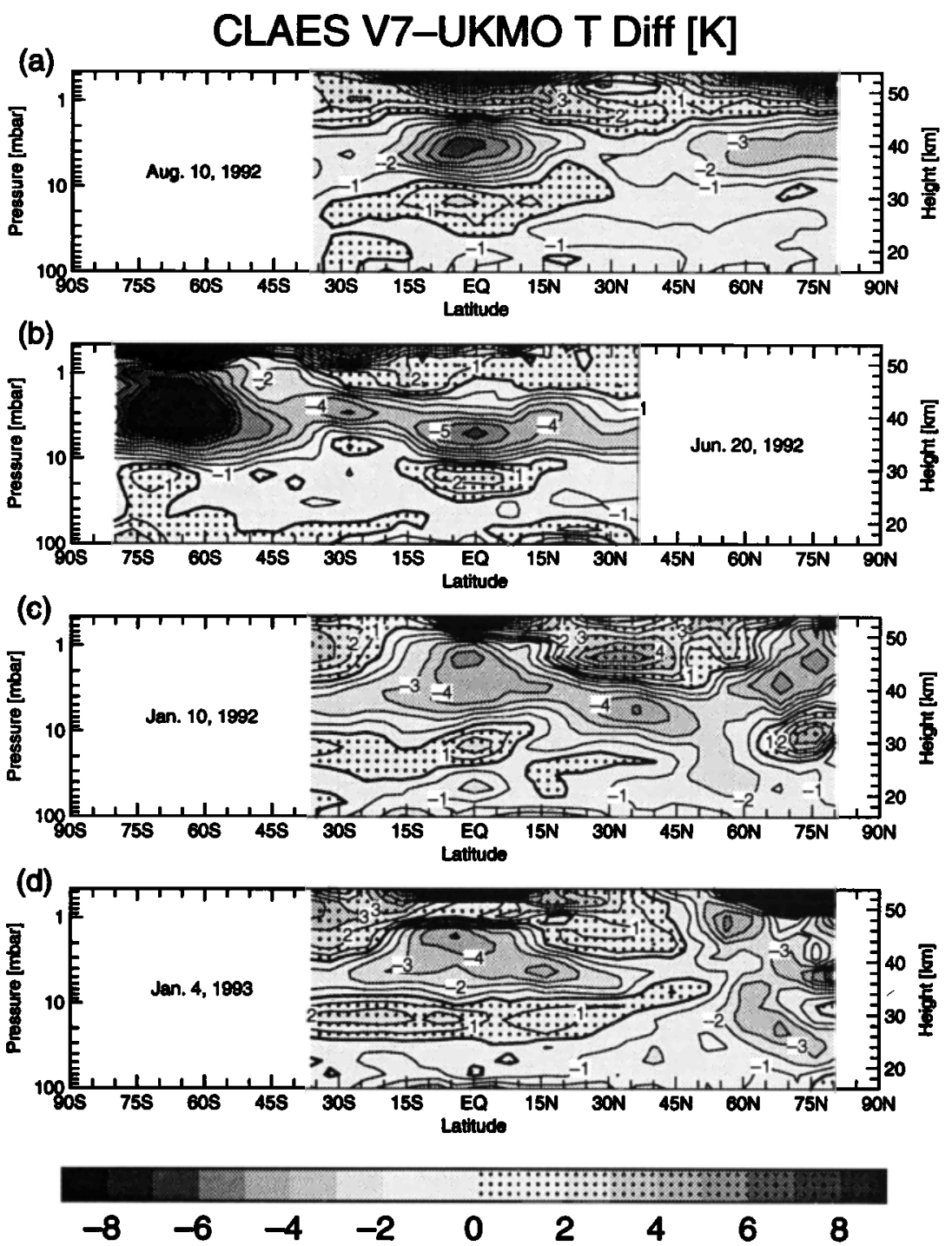

Figure 7. Latitude-pressure cross sections of CLAES V7 minus UKMO temperature; (a) August 10, 1992; (b) June 20, 1992; (c) January 10, 1992; (d) January 4, 1993.

ber of points, is $4.5 \mathrm{~K}$ at $190 \mathrm{~K}$. Some of the large negative outliers, especially in the SH, appear to be incorrect. However, CLAES results appear to be colder than the radiosondes in the SH midlatitudes and polar winter situations by more than they are in the NH. There is currently no explanation for these hemispheric differences.

\subsection{Comparisons Above the 10-mbar Pressure Level}

There are far fewer comparison measurements above 10 mbar than below, and they are primarily located in the $\mathrm{NH}$, and at midlatitudes. Thus these measurements cannot help to explain the differences between CLAES and NMC or UKMO in the SH polar winter.

Rocketsondes. There are far fewer ground-based measurements against which to compare temperatures at altitudes above 10 mbar. A decade or more ago, the only sources of comparison data above 10 mbar were rocketsondes [Gille et al., 1984]. In the intervening period, many rocket launch sites have been closed, and the number of launches has decreased at sites still active [Finger et al., 1993]. The development of ground-based lidar techniques and instrumentation for remotely measuring middle atmosphere temperatures has provided a replacement method. This has many different features, including many more measurements at a single point, and thus the possibility of looking more closely at time series.

The accuracy of the rocketsonde measurements is uncertain, especially above $50 \mathrm{~km}$ [Schmidlin, 1981]. Finger et al. [1993] give a precision of $1-3 \mathrm{~K}$. Time series of rocket and CLAES data at 1 mbar, for Cape Canaveral $\left(29^{\circ} \mathrm{N}\right)$ and Ryori, Japan $\left(39^{\circ} \mathrm{N}\right)$ (not presented), show that the CLAES data (within $2^{\circ}$ latitude, $5^{\circ}$ equivalent longitude, and 12 hours) track temporal variations in the rocket temperatures, notably the annual cycle.

Statistics on the differences for those launch sites, as well as Wallops Island $\left(38^{\circ} \mathrm{N}\right)$ and Ascension Island $\left(8^{\circ} \mathrm{S}\right)$ are pre- 

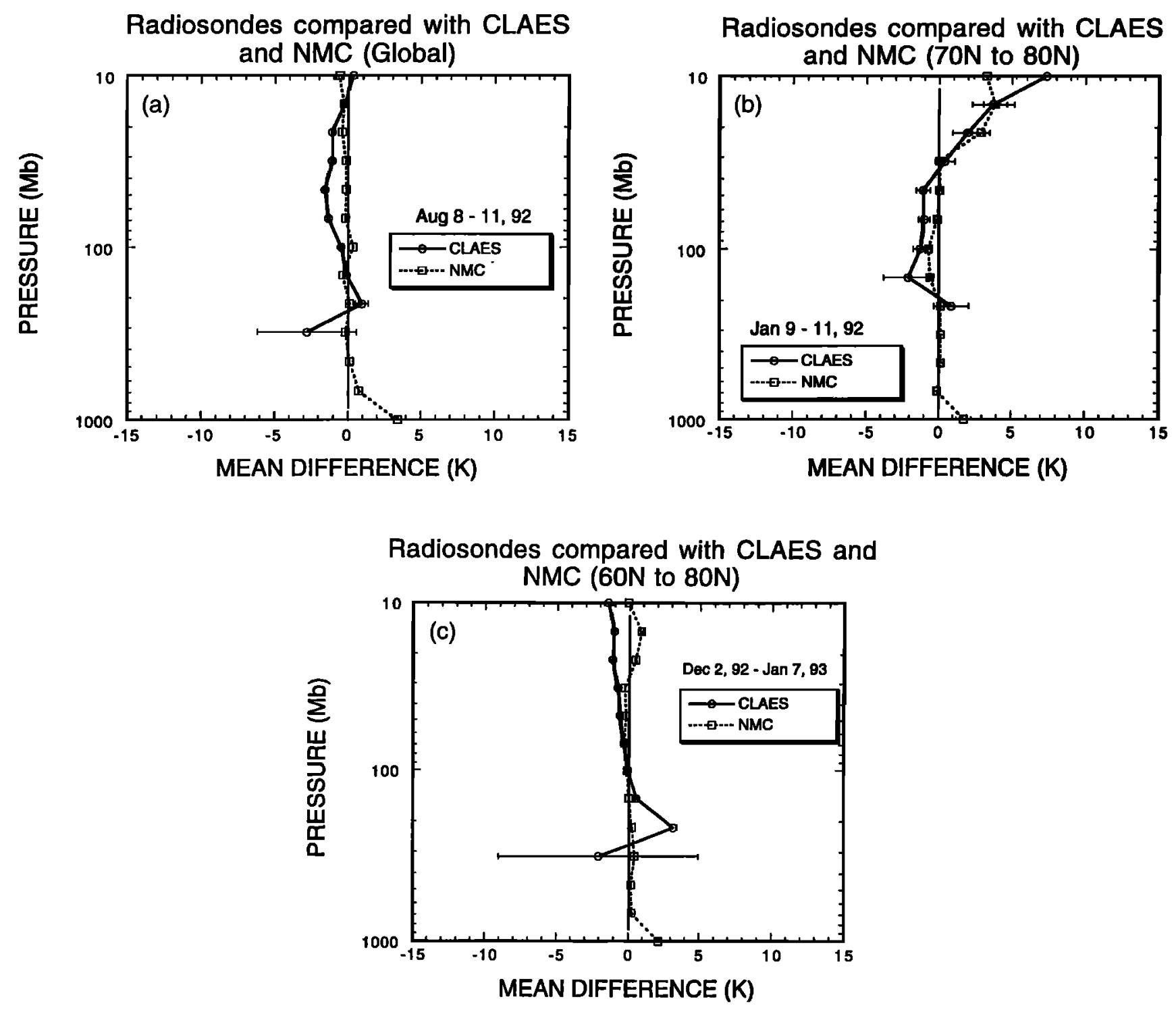

Figure 8. Mean CLAES minus radiosonde and NMC analysis minus radiosonde comparisons: (a) August 8-11, 1992, global, maximum/minimum number of comparisons; 545/28; (b) January 9-11, 1992 , $70^{\circ}-80^{\circ} \mathrm{N}, 91 / 3$; (c) December 2,1992 , to January $7,1993,60^{\circ}-80^{\circ} \mathrm{N}, 1211 / 248$.

sented in Figure 11. Here the coincidence criteria are $4^{\circ}$ latitude, $12^{\circ}$ of equivalent longitude, and 4 hours. These show agreement for the 75 soundings (one per week) within approximately $1 \mathrm{~K}$ from 10 to $1 \mathrm{mbar}$, with CLAES cooler by $2 \mathrm{~K}$ at 6.8 and 4.6 mbar. The results are quite similar when a 12-hour time window is used and 300 rocketsondes satisfy the coincidence criteria. CLAES is up to $7 \mathrm{~K}$ cooler than the rocketsondes above $0.46 \mathrm{mbar}$, in the low mesosphere. The agreement and consistency in the stratosphere are excellent.

Lidar temperature soundings. Lidar temperature sounding of the atmosphere is reviewed by Keckhut et al. [1993] and their compatibility with NMC analyses is discussed by Finger et al. [1993]. As a relatively new technique, lidar data are still the subject of active evaluation. The technique derives the temperatures from the vertical derivative of the density, which is determined from measurements of lidar radiation backscattered by atmospheric molecules. Because molecular Rayleigh backscattering coefficients are well known, the determinations have aspects of an absolute measurement system. However, different systems show somewhat different results, which requires caution in their use for comparisons. A comparison among the lidars used here is discussed by Wild et al. [1995].

Results from an extremely illuminating comparison from July 13 to August 18, 1992 at Observatoire de Haute Provence (OHP) in France $\left(44^{\circ} \mathrm{N}, 6^{\circ} \mathrm{E}\right)$ is shown in Figure 12a. Here the lidar soundings of the OHP lidar [Hauchecorne et al., 1991] were compared to 31 simultaneous soundings by the mobile lidar from Goddard Space Flight Center (GSFC) [Ferrare et al., 1995; McGee et al., 1995], 33 days of NMC and UKMO data, and 18 CLAES temperature retrievals. For CLAES the sounding compared was the closest within $4^{\circ}$ latitude, $12^{\circ}$ longitude, and 4 hours. First, note that the GSFC temperatures are in excellent agreement $(<1 \mathrm{~K})$ with OHP from 4.6 to 1 mbar, above which it is increasingly warmer, by up to $3.5 \mathrm{~K}$ at $0.1 \mathrm{mbar}$, which is still quite reason- 

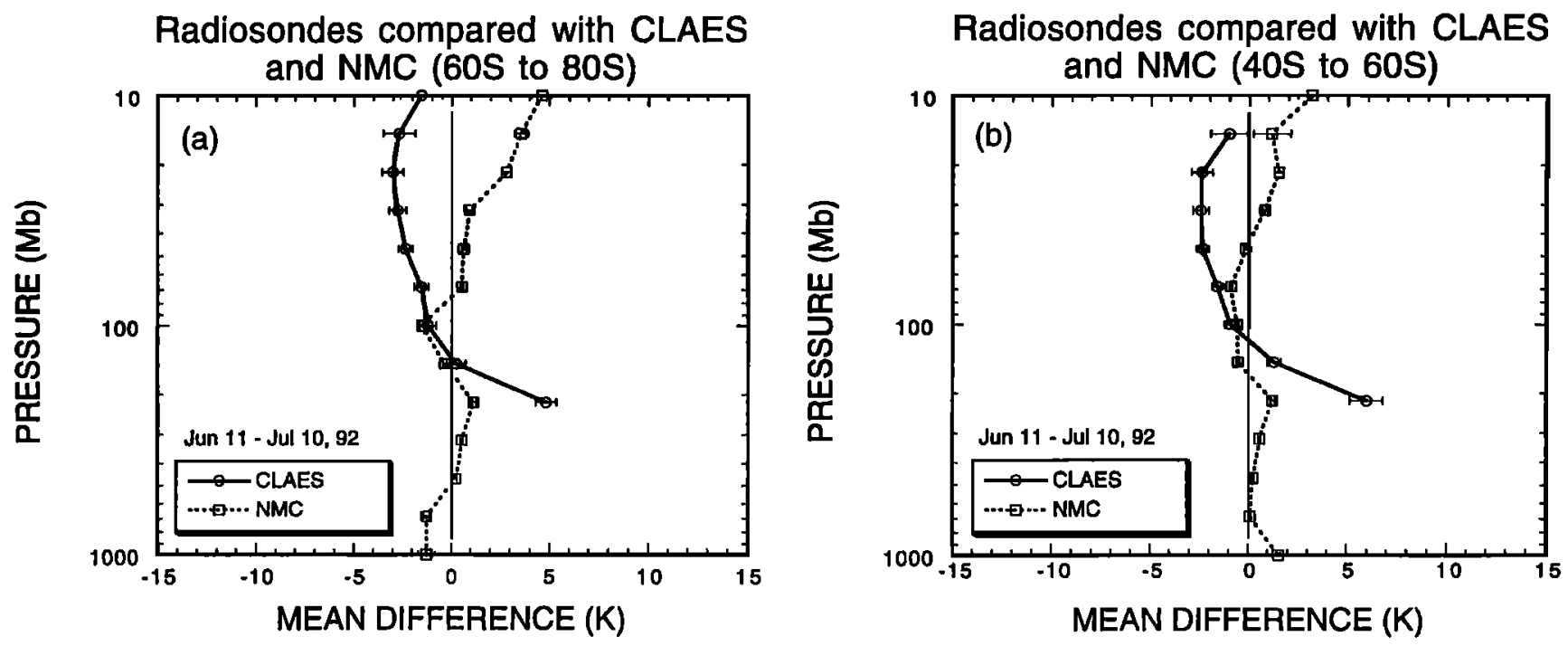

Figure 9. Average CLAES minus radiosonde comparisons: (a) June $11-\mathrm{July} 10,1992,60^{\circ}-80^{\circ} \mathrm{S}$, number of comparisons $102 / 11$; (b) June $11-\mathrm{July} 10,1992,40^{\circ}-60^{\circ} \mathrm{S}, 73 / 10$.

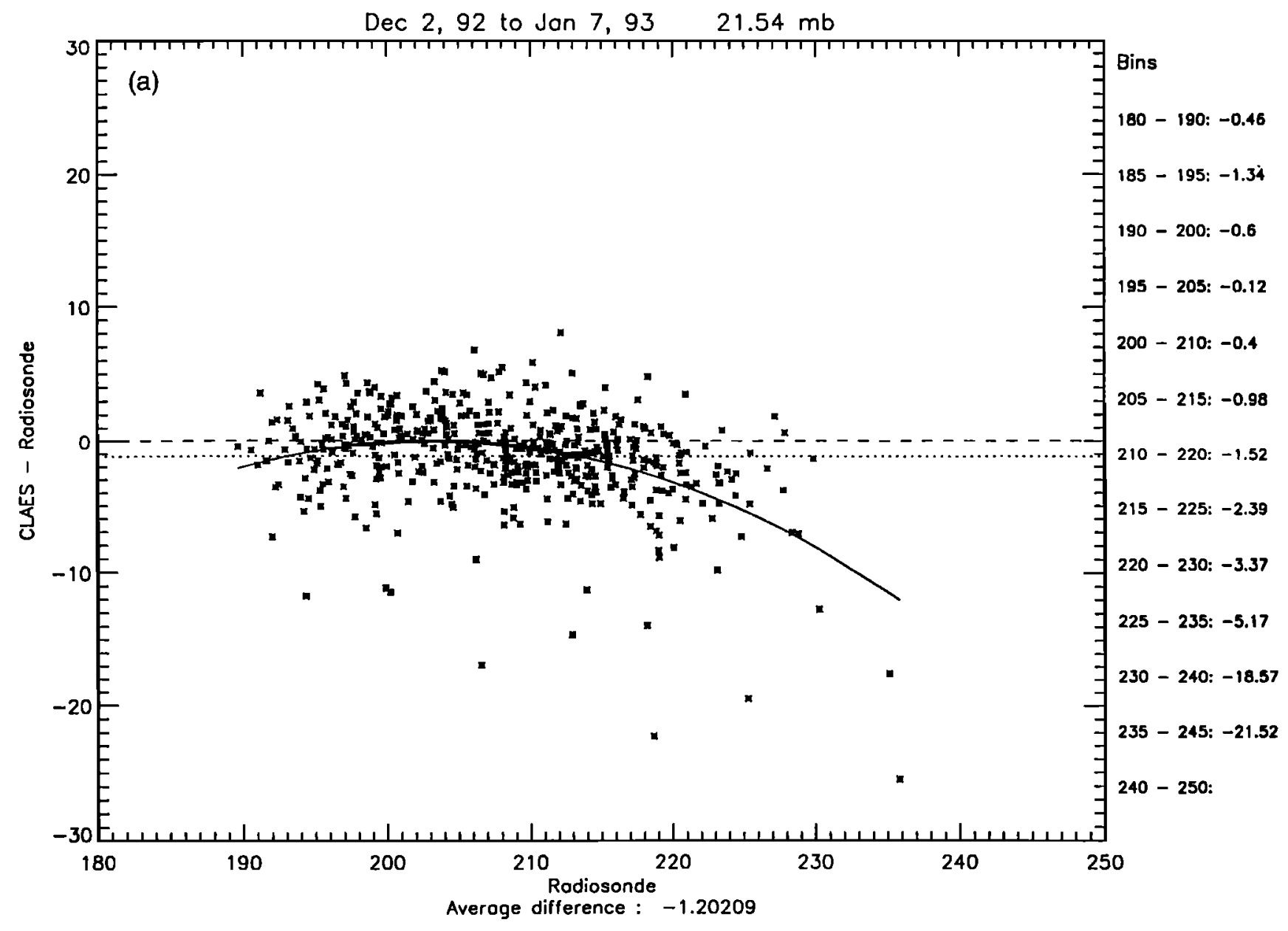

Figure 10. Plots of CLAES minus radiosonde versus radiosonde temperature at 21.5 mbar: (a) northern hemisphere, December 2, 1992, to January $7,1993,60^{\circ}-80^{\circ} \mathrm{N}$; (b) southern hemisphere, June 11-July 10, $1992,40^{\circ}-80^{\circ} \mathrm{S}$. Solid lines show a least squares fit; dashed line is mean difference. 


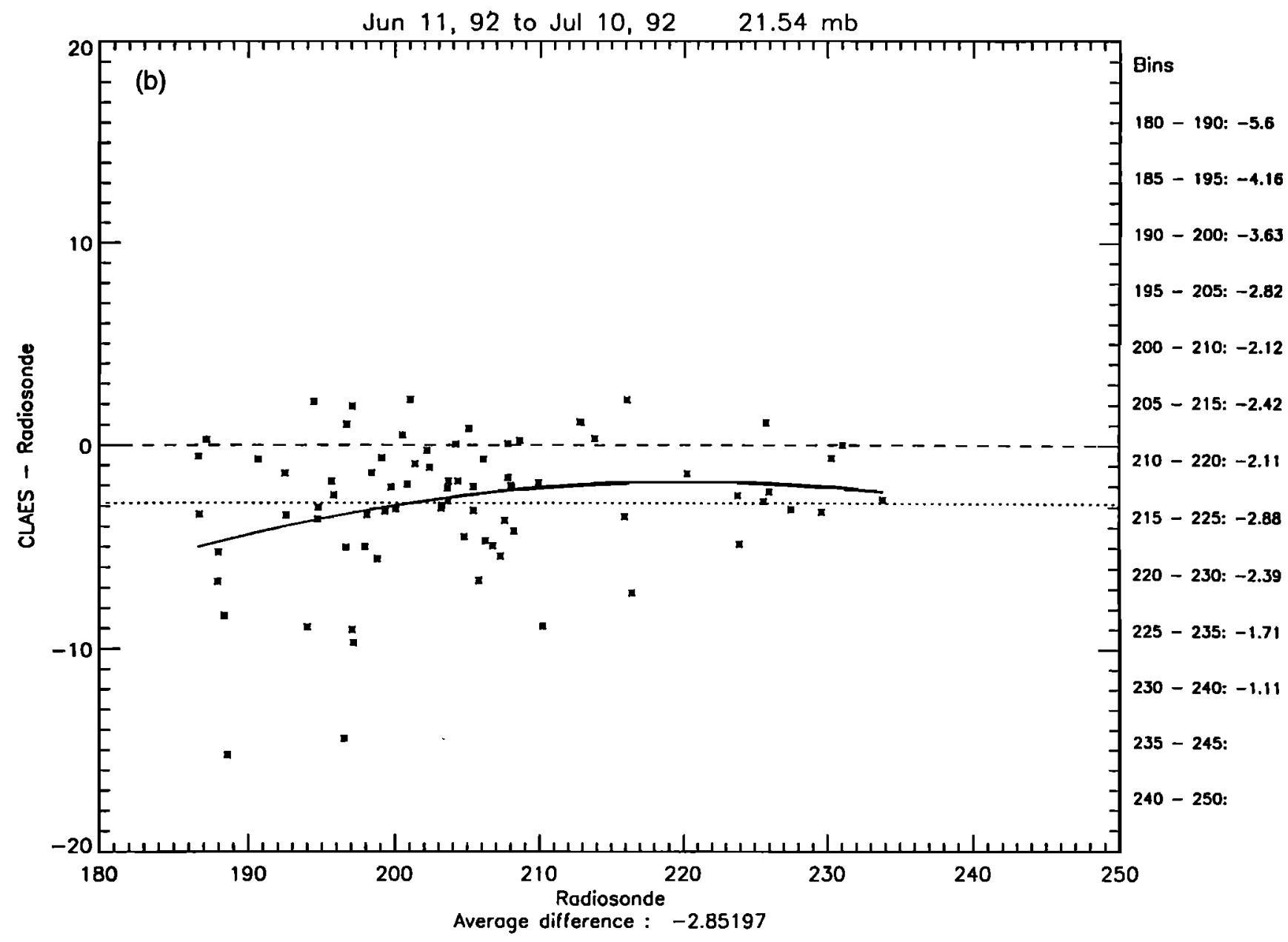

Figure 10. (continued)

able. The UKMO and NMC agree well (within $\approx 1 \mathrm{~K}$ ) with the GSFC lidar up to 1 and $1.4 \mathrm{mbar}$, respectively, above which they diverge, reflecting the lack of information in the TOVS radiances above this region. Below $4.6 \mathrm{mbar}$ the OHP temperatures are cooler than the other data.

Rocketsondes compared with CLAES

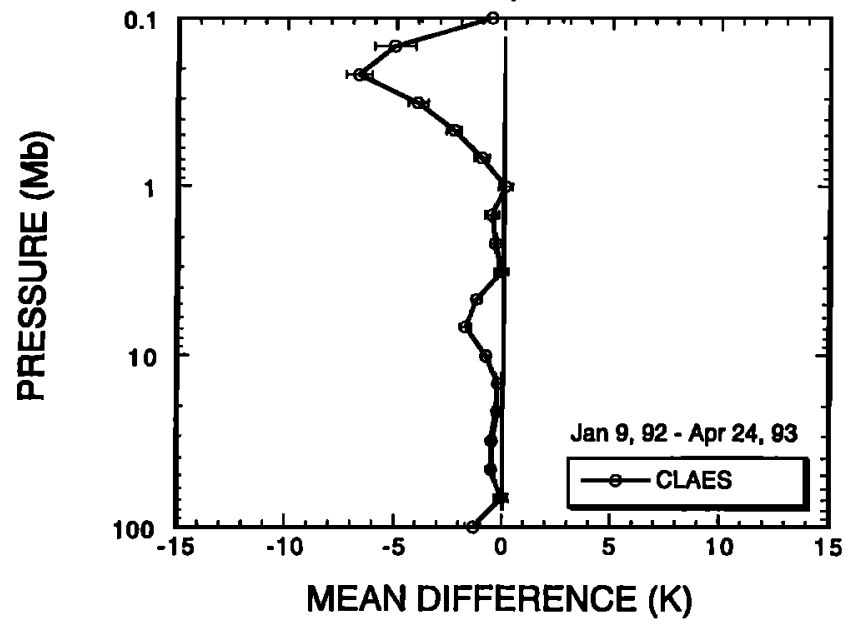

Figure 11. Statistics of CLAES minus rocketsondes, over the CLAES mission. Number of comparisons, 75/9.
CLAES is in good agreement $(<2 \mathrm{~K})$ with the GSFC lidar everywhere except for a layer near $3.1 \mathrm{mbar}$, where it is several degrees cooler than GSFC. Above 1 mbar, CLAES is warmer than OHP but in excellent agreement with the GSFC lidar except for a point at $0.21 \mathrm{mbar}$.

A similar comparison was made at Table Mountain Observatory (TMO) in California $\left(34^{\circ} \mathrm{N}, 118^{\circ} \mathrm{W}\right)$ from February 21 to March 19, 1992. The TMO lidar [McDermid, 1987] is compared to 24 GSFC lidar soundings, and $22 \mathrm{NMC}$, UKMO, and CLAES temperature profiles in Figure 12b. In this case, TMO is warm compared to GSFC at all levels and to UKMO and NMC at all levels below 1 mbar, perhaps because the measurements were not made simultaneously. In this case, CLAES temperatures agree well with GSFC, NMC, and to a lesser extent UKMO, from 10 to $1 \mathrm{mbar}$, and with GSFC to $0.31 \mathrm{mbar}$, above which it becomes warm compared to both GSFC and TMO. UKMO, NMC, and CLAES show a relatively cool region at 3 mbar, which GSFC shows only weakly.

Many factors determine the absolute accuracy of the lidar measurements, including different equipment, software, and levels of operation. Wild et al. [1995] show the importance of tidal effects in the spread of the comparison values. The OHPGSFC comparison [Singh et al., this issue] is probably an indication of the level of agreement that can eventually be achieved.

Comparisons of all 65 profiles at OHP for the period January 13 to September 16, 1992, are quite similar to those in 
OHP Lidar compared with CLAES, NMC, UKMO and GSFC Lidar

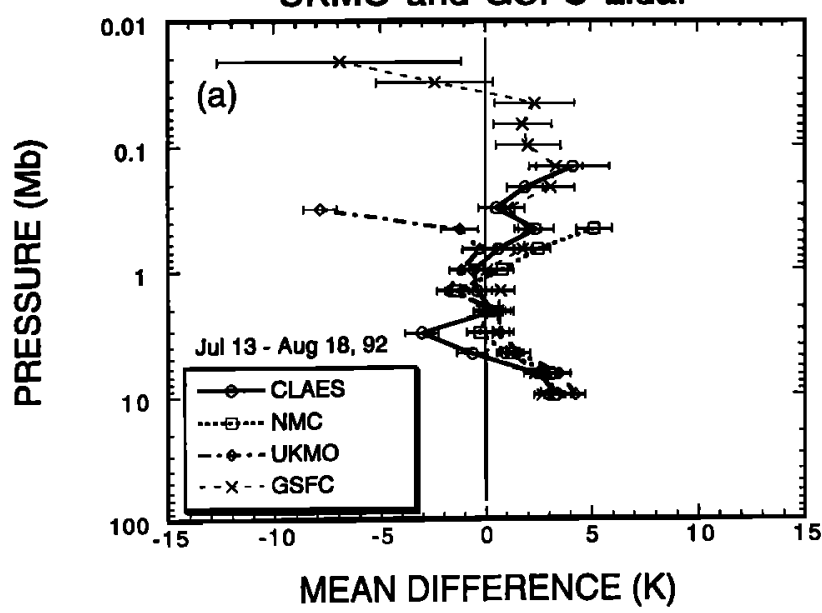

TMO lidar compared with CLAES, NMC, UKMO and GSFC lidar

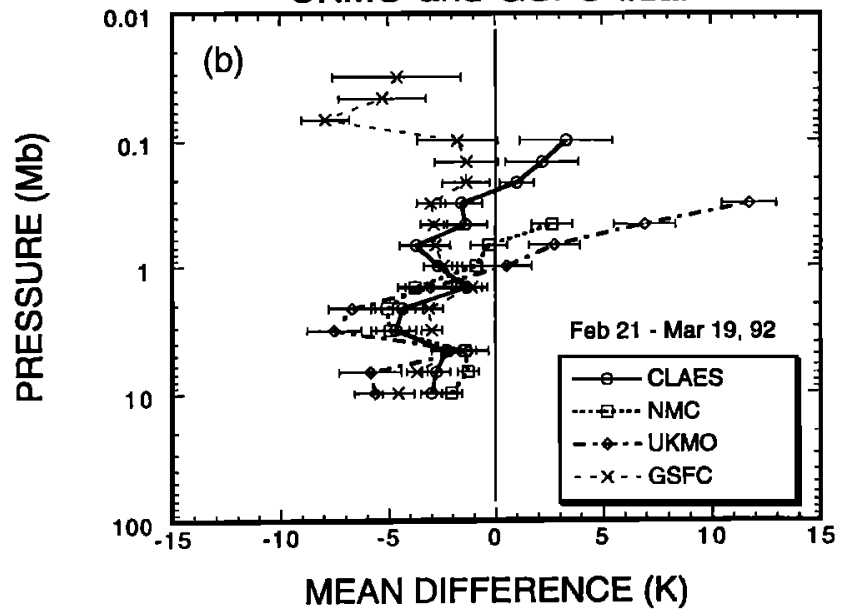

Figure 12. Intercomparisons among temperatures obtained from lidar, analyzed operational satellite data, and CLAES. (a) Average of temperatures from other sources minus that from the lidar at Observatoire de Haute Province (OHP), $\left(44^{\circ} \mathrm{N}\right.$, $6^{\circ} \mathrm{E}$ ), for the period July $13-$ August 18,1992 , and $\operatorname{SD}(\bar{x})$ values; (b) Average of temperatures from other sources minus that from the lidar at Table Mountain Observatory (TMO), $\left(34^{\circ} \mathrm{N}, 118^{\circ} \mathrm{W}\right)$, for the period February 21-March 19, 1992, and $\operatorname{SD}(\bar{x})$ values.

Figure 12a, although the cool layer of CLAES compared to OHP is deeper below $3.1 \mathrm{mbar}$. These lidar soundings were averaged over a short period around the overpass time. Subsequent to mid-September, OHP profiles were averaged over several hours. The statistics of including these, and spanning the entire useful CLAES V7 data period from January 9, 1992 through April 29, 1993 (116 profiles), are displayed in Figure 13a. Again, CLAES is warmer than OHP at $10 \mathrm{mbar}$ (which may be due do volcanic aerosols, although why this does not affect GSFC is not clear) and above $1 \mathrm{mbar}$. The cool layer at 4.6 mbar is barely perceptible.

A similar comparison for the lidar at Biscarrosse $\left(44^{\circ} \mathrm{N}\right.$, $1^{\circ} \mathrm{W}$ ) is shown in Figure 13b. Like its neighbor at $\mathrm{OHP}$, it is
OHP lidar compared with CLAES, NMC and UKMO
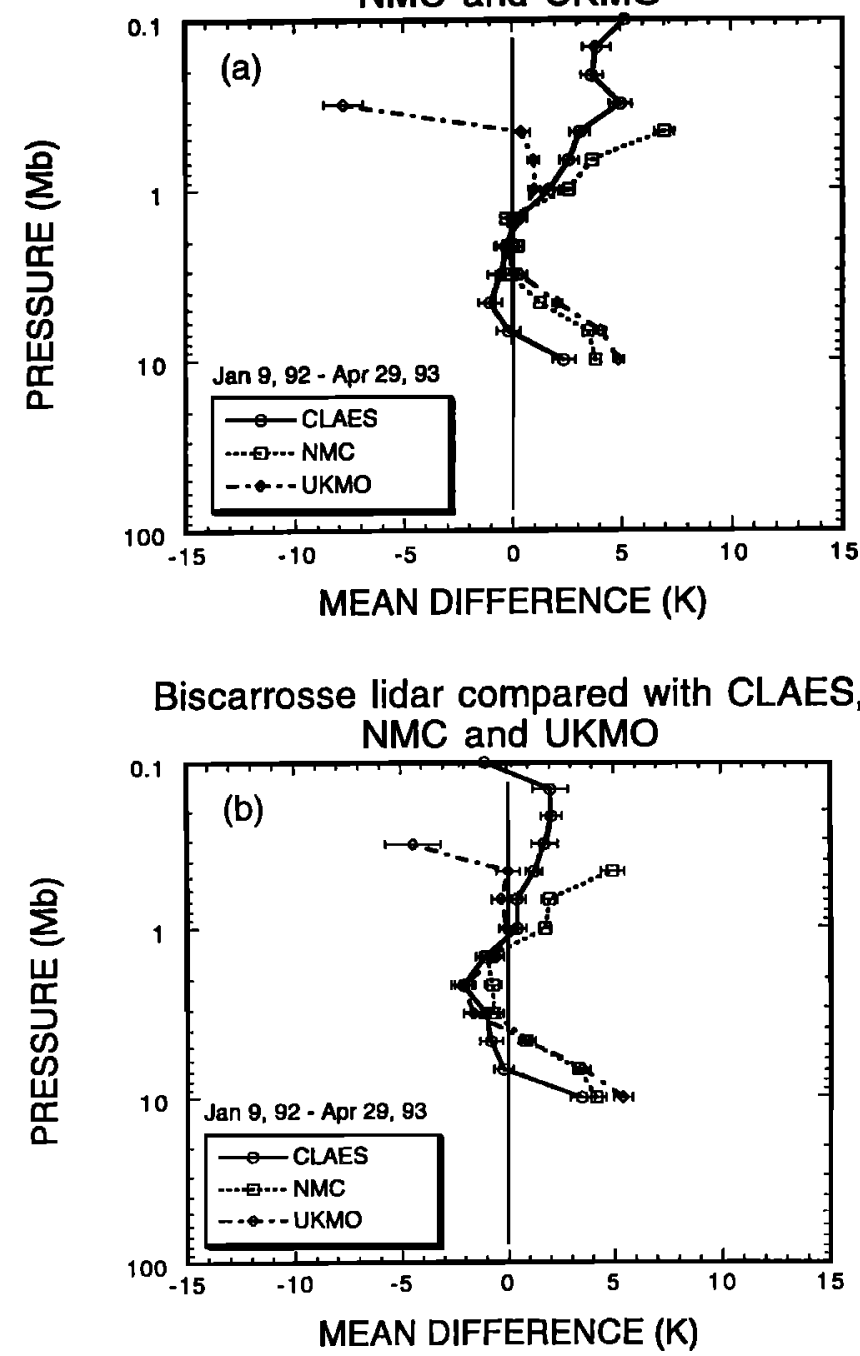

TMO lidar compared with CLAES, NMC and UKMO

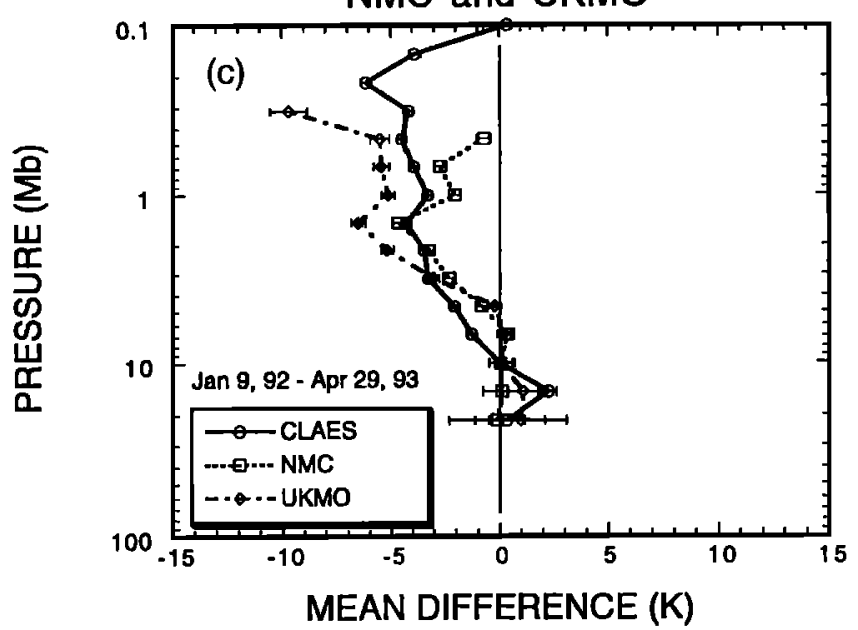

Figure 13. CLAES minus lidar temperature differences averaged over the CLAES V7 data period, January 9 1992, to April 29,1993 , and $\operatorname{SD}(\bar{x})$ values. (a) OHP (116 CLAES comparisons); (b) Biscarrosse (93 CLAES comparisons); (c) TMO (595 CLAES comparisons). 
cooler than other data at 10 mbar but agrees within $2 \mathrm{~K}$ with CLAES from 6 to 0.1 mbar. Again, CLAES (and UKMO) is cooler than the lidar and NMC at 2 and 3 mbar.

The long-term comparison with TMO (Figure 13c) indicates that CLAES agrees within $2 \mathrm{~K}$ with UKMO and NMC from 10 to $1 \mathrm{mbar}$ but that those three, while in excellent agreement with TMO at $10 \mathrm{mbar}$, are about $5 \mathrm{~K}$ cooler than TMO at the stratopause.

Taken together, these data indicate that CLAES is generally in good $(\approx 2 \mathrm{~K})$ agreement with the lidars and other data from 10 to 2 mbar but with a tendency to have a narrow layer that is cooler than the comparison data somewhere between 4.6 and 2.1 mbar, suggesting that some of the differences seen in the cross sections in this region are due to a CLAES artifact which is not understood at present.

A critical deficiency is that all but one (tropical) of the correlative measurements above 10 mbar are located between $29^{\circ} \mathrm{N}$ and $44^{\circ} \mathrm{N}$; that is, there are none in the polar regions, in which the largest departures from the analyses take place. This will have to be addressed through a comparison with other UARS data.

\section{Conclusions}

CLAES temperature retrievals are based on limb emission by $\mathrm{CO}_{2}$, the same method used by several other experiments, although the $792 \mathrm{~cm}^{-1} Q$ branch rather than the $667-\mathrm{cm}^{-1}$ band complex is measured. The signal level at the top is only 2 orders of magnitude smaller than at the bottom, so the measured $10^{-4}$ out-of-field response contributes but a very small error to the signals at the highest detectors, and there is good signal-to-noise ratio at almost all levels.

The retrieval requires auxiliary meteorological data, essentially to provide pressure tie-on data. The V7 retrieval uses NMC temperatures and thus may be sensitive to any errors in them. Further, by requiring agreement between mean CLAES and NMC temperatures between 100 and $10 \mathrm{mbar}$, there should be very small differences at these levels. This is usually true, but it is violated in SH winter situations for reasons which are not understood at this time; this is currently under investigation with the intent to improve future versions.

The repeatability or random errors in the retrievals have been estimated from the RMS of the difference between pairs of retrievals at the same location, near $32^{\circ} \mathrm{N}$ or $32^{\circ} \mathrm{S}$, on sequential orbits, $96 \mathrm{~min}$ apart. This procedure leads to values between about $0.8 \mathrm{~K}$ at $68 \mathrm{mbar}$ and roughly $3-3.5 \mathrm{~K}$ at 0.2 mbar. Simulations, based on observed noise levels and spacecraft motion, are in good agreement with the observed values, supporting the identification of these processes as the major sources of the random errors.

CLAES temperature fields are in good agreement $(\approx 2-3 \mathrm{~K}$ ) with NMC and UKMO global analyses, except during polar winters, in the tropics, and in high latitudes near $40 \mathrm{~km}$ altitude, where CLAES is cooler. The differences in the tropics are due to tropical waves, which have vertical wavelengths too short to be seen in the TOVS data and the analyses based on them but which can be resolved by CLAES.

Local measurements have been used to try to resolve the remaining differences. Comparisons with radiosondes, rocketsondes and lidars generally agree with each other and with the global analyses, in showing CLAES in good agreement, but cooler by about $2 \mathrm{~K}$.
In the SH below 10 mbar, CLAES is cold compared to the NMC. However, the analyses are warm compared to radiosondes, so CLAES is probably not so far below the true temperature as suggested by the analyses. CLAES temperatures tend to drop farther below radiosondes as the temperatures get colder. There is a bias in the parameterized transmittances that is as large as $4 \%$ that may cause the CLAES retrievals to be too cold when the temperature is extremely low.

Comparisons with lidars (all between $29^{\circ} \mathrm{N}$ and $44^{\circ} \mathrm{N}$ ) hint at narrow regions near $40 \mathrm{~km}$ where CLAES is cooler than the lidar temperatures. This difference, for which there is currently no explanation, is under investigation. The lack of lidar or rocket measurements at high latitudes makes it impossible on the basis of the data discussed here to explain the larger regions of differences in the polar winter stratosphere.

In conclusion, extratropical CLAES temperatures, compared to a wide range of correlative information, are generally cooler by up to $2 \mathrm{~K}$, but differences with NMC analyses are larger in the polar regions, especially during winter conditions, where there are no conventional correlative data to resolve the problem. Intercomparison of UARS data should help to resolve this question.

Acknowledgments. We acknowledge the contributions of Richard Swinbank and Alan O'Neill for making the data from the U.K. Meteorological Office assimilation available to the UARS investigators and for helpful comments. Thanks are also due to Daniel Packman for mapping the CLAES data, Cheryl Craig and Charles Cavanaugh for carrying out the comparisons between CLAES and in situ sensors, and Arun Gopalan for noise simulations. The work at NCAR was supported by the National Aeronautics and Space Administration under Interagency Agreement S-10782. The National Center for Atmospheric Research is sponsored by the National Science Foundation.

\section{References}

Bailey, P. L., et al., A comparison of Cryogenic Limb Array Etalon Spectrometer (CLAES) $\mathrm{O}_{3}$ observations with correlative measurements, J. Geophys. Res., this issue.

Ferrare, R. A., et al., Lidar measurements of stratospheric temperature during STOIC, J. Geophys. Res., 100, 9303-9312, 1995.

Finger, F. G., M. E. Gelman, J. D. Wild, M. L. Chanin, A. Hauchecorne, and A. J. Miller, Evaluation of NMC upper-stratospheric temperature analyses using rocketsonde and lidar data, Bull. Am. Meteorol. Soc., 74, 789-797, 1993.

Gelman, M. E., A. J. Miller, R. N. Nagatani, and C. S. Long, Use of UARS data in the NOAA stratospheric monitoring program, Adv. Space Res., 14, (9)21-(9)31, 1994.

Gille, J. C., and F. B. House, On the inversion of limb radiance measurements, I, Temperature and thickness, J. Atmos. Sci., 28, 1427 $1442,1971$.

Gille, J. C., J. M. Russell III, P. L. Bailey, L. L. Gordley, E. E. Remsberg, J. H. Lienesch, W. G. Planet, F. B. House, L. V. Lyjak, and S. A. Beck, Validation of temperature retrievals obtained by the Limb Infrared Monitor of the Stratosphere (LIMS) experiment on Nimbus 7, J. Geophys. Res., 89, 5147-5160, 1984.

Hauchecome, A., M. L. Chanin, and P. Keckhut, Climatology and trends of the middle atmospheric temperature $(33-87 \mathrm{~km})$ as seen by Rayleigh lidar over the south of France, J. Geophys. Res., 96, 15,297-15309, 1991.

James, T. C., A. E Roche, and J. B. Kumer, Model calculations of spectral transmission for the CLAES etalons, Proc. Soc. Photo-Opt. Instrum. Eng., 973, 353-360, 1988.

Johns, J. W. C., Intensities of $\mathrm{CO}_{2}$ bands: Have we come to the end of the road?, J. Quant. Spectrosc. Radiat. Transfer, 48, 567-572, 1992. 
Keckhut, P. A., A. Hauchecome, and M. L. Chanin, A critical review of the data base acquired for the long-term surveillance of the middle atmosphere by the French Rayleigh lidars, J. Atmos. Oceanic Technol., 10, 850-867, 1993.

Kohri, W. J., LRIR observations of the structure and propagation of the stationary planetary waves in the Northern Hemisphere during December 1975. Ph.D. thesis, Drexel Univ., Cooperative thesis 63, Natl. Cent. for Atmos. Res., Boulder, Colo., 1981.

Kumer, J. B., and J. L. Mergenthaler, Pressure, temperature, and ozone profile retrieval from simulated atmospheric earth-limb infrared emission, Appl. Opt., 30, 1124-1131, 1991.

Kumer, J. B. J. L. Mergenthaler, T. C. James, A. E. Roche, L. W. Sterritt, and J.F. Potter, Detector channeling hypothesis for enhanced structure observed in CLAES system blocker filter functions, paper presented at the Topical Meeting on Optical Remote Sensing of the Atmosphere, Opt. Soc. of Am., Incline Village, Nev., February 12-15, 1990.

Kumer, J. B., J. L. Mergenthaler, and A. E. Roche, CLAES $\mathrm{CH}_{4}, \mathrm{~N}_{2} \mathrm{O}$ and $\mathrm{CF}_{2} \mathrm{Cl}_{2}$ (F12) global data, Geophys. Res. Lett., 20 , 1239-1242, 1993.

Kumer, J. B., et al., Comparison of correlative data with nitric acid data version 7 from the Cryogenic Limb Array Etalon Spectrometer (CLAES) instrument deployed on the NASA Upper Atmosphere Research Satellite, J. Geophys. Res., this issue.

Manney, G. L., R. Swinbank, S. T. Massie, M. E. Gelman, A. J. Miller, R. Nagatani, A. O'Neill, and R. W. Zurek, Comparison of UKMO and NMC stratospheric analyses during northem and southern winter, J. Geophys. Res., this issue.

Marshall, B. T., L. L. Gordley, and D. A.Chu, BANDPAK: Algorithms for modeling broadband transmittance and radiance, $J$. Quant. Spectrosc. Radiat. Transfer, 52, 563-580, 1994.

Massie, S. T., J. C. Gille, P. L. Bailey, E. C. Lee, J. L. Mergenthaler, A. E. Roche, J. B. Kumer, E. F. Fishbein, J. W. Waters, and W. A. LaHoz, Spectral signatures of polar stratospheric clouds and sulfate aerosol, J Atmos. Sci., 51, 3027-3044, 1994.

Massic, S. T., et al., Validation studies using multi-wavelength Cryogenic Limb Array Etalon Spectrometer (CLAES) observations of stratospheric aerosol, J. Geophys. Res., this issue

McDermid, I. S., Ground-based lidar and atmospheric studıes, Surv. Geophys., 9, 107-122, 1987.

McGee, T. J., M. R. Gross, U. N. Singh, J. J. Butler, and P. E. Kimvilakani, Improved Stratospheric Ozone Lidar, Opt. Eng., 34, 1421-1430, 1995 .

Mergenthaler, J. L., J. F. Potter, J. B. Kumer, T. C. James, and A. E. Roche, Retricval of CLAES filter shapes from spectral calibration data, paper presented at the Topical Meeting on Optical Remote Sensing of the Atmosphere, Opt. Soc. of Am., Incline Village, Nev., February 12-15, 1990.

Mergenthaler, J. L., J. B. Kumer, and A. E. Roche, CLAES sout'looking aerosol observations for 1992, Geophys. Res. Lett., 20, 12951298, 1993.

Nash, J., and F. J. Schmidlın, Final report of the WMO International Radiosonde Intercomparison, WMO Rep. 30, 123 pp., World Meteorol. Organ., Geneva, 1987.

Reber, C. A., The Upper Atmosphere Research Satellite, Geophys. Res. Lett., 20, 1215-1218, 1993.

Reber, C. A.., C. E. Trevathan, R. J. McNeal, and M. R. Luther, The Upper Atmosphere Research Satellite (UARS) mission, J. Geophys. Res., 98, 10,643-10,647, 1993.
Roche, A. E., J. B. Kumer, J. L. Mergenthaler, G. A. Ely, W. G. Uplinger, J. F. Potter, T. C. James, and L. W. Sterritt, The Cryogenic Limb Array Etalon Spectrometer (CLAES) on UARS: Experiment description and performance, J. Geophys. Res., 98, 10,763-10,775, 1993.

Roche, A. E., J. B. Kumer, and J. L. Mergenthaler, R. W. Nightingale, W. G. Uplinger, G. A. Ely, J. F. Potter, D. J. Wueblles, P. S. Connell, and D. E. Kinnison, Observations of lower stratospheric $\mathrm{ClONO}_{2}$, $\mathrm{HNO}_{3}$ and aerosol by the UARS CLAES experiment between January 1992 and April 1993, J. Atmos. Sci., 51, 2877-2902, 1994.

Rodgers, C., Retrieval of atmospheric temperature and composition from remote measurements of thermal radiation, Rev. Geophys., 14, 609-624, 1976.

Rothman, L. S., R. L. Hawkins, R. B. Watson, and R. R. Gamache, Energy levels and linewidths of atmospheric carbon dioxide bands, J. Quant. Spectrosc. Radiat. Transfer, 48, 537-566, 1992.

Schmidlin, F. J., Repeatability and measurement uncertainty of the United States meteorological rocketsonde, J. Geophys. Res., 86, 9599-9603, 1981.

Singh, U. N., P. Keckhut, T. J. McGee, M. Gross, A. Hauchecorne, E. F. Fishbein, J. W. Waters, J. C. Gille, A. E. Roche, and J. M. Russell, Stratospheric temperature measurements by two collocated NDSC lidars at OHP during UARS validation campaign, J. Geophys. Res., this issue.

Smith, W. L., H. M. Woolf, C. M. Hayden, D. Q. Wark, and L. W. McMillin, The TIROS-N operational vertical sounder, Bull. Am. Meteorol. Soc., 60, 1177-1187, 1979.

Sterritt L. W., T. C. James, J. B. Kumer, A. E. Roche, B. C. Steakley, and K. M. Zickuhr, Cryogenic Limb Array Etalon Spectrometer (CLAES) calibration, Proc. Soc. Photo-Opt. Instrum. Eng., 1340, 194-202, 1990.

Swinbank, R., and A. O'Neill, A stratosphere-troposphere data assimilation system, Mon. Weather Rev., 122, 686-702, 1994.

Wild, J. D., et al., Comparison of stratospheric temperature from several lidars, using NMC and MLS data as transfer reference, J. Geophys. Res., 100, 11,105-11,111, 1995.

P L. Bailey, D. P. Edwards, J. C Gille (corresponding author), L. V. Lyjak, and S. T. Massie, National Center for Atmospheric Research, P.O. Box 3000, Boulder, CO 80307.

R. Gross and U. Singh, Hughes STX Corporation, Lanham, MD 20706.

A. Hauchecorne and P. Keckhut, Service d'Aéronomie du CNRS,

Vérricres-Le Buisson, France.

P. Keckhut and A. Miller, Climate Analysis Center,

NMC/NWS/NOAA, Washington, DC 20233.

J. B. Kumer, J. L. Mergenthaler, and A. E. Roche, Lockheed Palo

Alto Research Laboratory, Palo Alto, CA 94304.

T. J. McGee, NASA Goddard Space Flight Center, Greenbelt, MD 20771.

I. S. McDermid, Jet Propulsion Laboratory, California Institute of Technology, Pasadena, CA 91109.

(Received August 18, 1995; revised December 15, 1995; accepted December 21, 1995.) 